\title{
Excusing Selfishness in Charitable Giving: The Role of Risk
}

\section{Citation}

Exley, Christine L. "Excusing Selfishness in Charitable Giving: The Role of Risk." Review of Economic Studies 83, no. 2 (April 2016): 587-628. doi:10.1093/restud/rdv051.

\section{Published Version}

10.1093/restud/rdv051

\section{Permanent link}

http://nrs.harvard.edu/urn-3:HUL.InstRepos:34816658

\section{Terms of Use}

This article was downloaded from Harvard University's DASH repository, and is made available under the terms and conditions applicable to Open Access Policy Articles, as set forth at http:// nrs.harvard.edu/urn-3:HUL.InstRepos:dash.current.terms-of-use\#OAP

\section{Share Your Story}

The Harvard community has made this article openly available.

Please share how this access benefits you. Submit a story.

Accessibility 


\title{
Excusing Selfishness in Charitable Giving: The Role of Risk
}

\author{
Christine L. Exley *
}

September 7, 2015

\begin{abstract}
Decisions involving charitable giving often occur under the shadow of risk. A common finding is that potential donors give less when there is greater risk that their donation will have less impact. While this behavior could be fully rationalized by standard economic models, this paper shows that an additional mechanism is relevant: the use of risk as an excuse not to give. In a laboratory study, participants evaluate risky payoffs for themselves and risky payoffs for a charity. When their decisions do not involve tradeoffs between money for themselves and the charity, they respond very similarly to self risk and charity risk. By contrast, when their decisions force tradeoffs between money for themselves and the charity, participants act more averse to charity risk and less averse to self risk. These altered responses to risk bias participants towards choosing payoffs for themselves more often, consistent with excuse-driven responses to risk. Additional results support the existence of excuse-driven types.
\end{abstract}

Keywords: charitable giving; prosocial behavior; altruism; risk preferences

*Exley, Harvard Business School; clexley@hbs.edu. Acknowledgements: I gratefully acknowledge funding for this study from the NSF (SES \# 1159032), the Stanford Economics Department, the Stanford Center on Philanthropy and Civil Society, and the Stanford Institute for Economic Policy Research via the E.S. Shaw \& B.F. Haley Fellowship. For helpful advice, I would like to thank participants at the Stanford Institute for Theoretical Economics Workshops, the Experimental Sciences Association Annual Conferences, the Stanford Behavioral Seminars and Lunches, as well as the editor, three anonymous referees, B. Douglas Bernheim, Katherine Coffman, Lucas Coffman, Paul J. Healy, Muriel Niederle, Alvin Roth, Charles Sprenger, and Stephen Terry. 


\section{Introduction}

In the United States, 1 in 4 adults volunteer and 1 in 2 adults give to charities for an estimated combined value of $\$ 500$ billion dollars per year. ${ }^{1}$ An established literature documents potential motives for such giving; for instance, people feel good about themselves when they help others (Andreoni, 1989, 1990), value appearing nice to others (Harbaugh, 1998a; Bénabou and Tirole, 2006; Ariely et al., 2009), and desire to conform with social norms (Andreoni and Bernheim, 2009). ${ }^{2}$ These motives, as well as standard economic models, may easily explain a common finding in charitable giving: individuals give less when when there is a greater risk that their donation will have less impact (Brock et al., 2013; Krawczyk and Lec, 2010). ${ }^{3}$ In this paper, however, I investigate whether an additional mechanism is relevant: do people use the risk that their donation may have less than the desired impact as an excuse not to give?

Given how often people are asked to give - over $50 \%$ of adults report being asked more than three times within the past year - reluctant individuals may desire an excuse not to give. ${ }^{4}$ Previous literature in fact demonstrates a large scope for motivations broadly related to excuses. For instance, people often behave more selfishly when they can avoid learning how their decisions affect others (Dana et al., 2007; Bartling et al., 2014; Grossman, 2014), develop self-serving biases (Konow, 2000; Haisley and Weber, 2010), or rely on the possibility that their decisions did not influence the outcome (Dana et al., 2007; Andreoni and Bernheim, 2009; Linardi and McConnell, 2011; Falk and Szech, 2013). ${ }^{5}$ People also achieve more selfish outcomes by delegating decisions to others (Hamman et al., 2010; Coffman, 2011; Bartling and Fischbacher, 2012), or by avoiding situations that involve giving decisions (Dana et al., 2006; Broberg et al., 2007; Andreoni et al., 2011; Lazear et al., 2012; DellaVigna et al., 2012). ${ }^{6}$

This paper differentiates itself from existing literature by documenting self-serving responses

\footnotetext{
${ }^{1}$ http://www.volunteeringinamerica.gov/infographic.cfm, http://www.givingusareports.org/.

${ }^{2}$ For an overview of these reasons as well as others, see surveys in Vesterlund (2006) and Andreoni (2006).

${ }^{3}$ While Brock et al. (2013) and Krawczyk and Lec (2010) involve objective risk in a dictator game, other studies document reduced giving in response to other types of risk or uncertainty, involving performance metrics (Yörük, 2013; Meer, 2014; Brown et al., 2014; Karlan and Wood, 2014), the use of donations (Gneezy et al., 2014; Batista et al., 2015), and the recipient of donations (Small and Loewenstein, 2003; Fong and Oberholzer-Gee, 2011; Li et al., 2013).

${ }^{4}$ Results are from a Google Consumer Survey I ran in Sept. - Nov. 2014. 505 individuals answered "Within the past year, approximately how many times have you been asked - whether in person or via other means, such as emails or social media - to donate money to a charity?" $51 \%$ of respondents answered 3 or more times.

${ }^{5}$ van der Weele et al. (2014) documents a limitation of these results in the context of reciprocal behavior. Some of this work also ties into image motivation that often leads people to behave more selfishly when there is less observability of their action, such as discussed in Harbaugh (1998b,a); Andreoni and Petrie (2004); Bénabou and Tirole (2006); Andreoni and Bernheim (2009); Ariely et al. (2009); Lacetera and Macis (2010); Linardi and McConnell (2011); Exley (2014). There is also a relatedly rich literature in psychology on moral licensing (see Merritt et al. (2010) for a nice overview).

${ }^{6}$ Moreover, Andreoni and Rao (2011) and Castillo et al. (2014) show that asking people to give increases donations. Oberholzer-Gee and Eichenberger (2008) finds that just the option to avoid giving decisions - by choosing to play a lottery instead of a dictator game - can also lead to reduced giving.
} 
to objective risk in a social setting absent other factors, such as image concerns (Andreoni and Bernheim, 2009), information acquisition (Dana et al., 2006), ambiguity (Haisley and Weber, 2010), or actions of others (Falk and Szech, 2013). In exploiting a within-subject experimental design, this paper also provides evidence for an individual level of consistency in self-serving tendencies. Motivated by related policy questions, this paper somewhat less commonly focuses on charitable giving decisions, but as verified in an additional study involving payoffs for other participants instead of a charity, it seeks to contribute to the broader other-regarding literature.

To begin, this paper conducts a laboratory study that allows for the needed control to isolate excuse-driven responses to risk from other responses to risk. Participants make a series of binary decisions between risky and riskless payoffs that may benefit themselves or the American Red Cross. A risky payoff is a lottery that yields a non-zero amount with probability $P$ and $\$ 0$ with probability $1-P$. A risky payoff is a "charity lottery" or a "self lottery" if the corresponding outcome is given to the American Red Cross or the participant, respectively. ${ }^{7}$ A riskless payoff yields a non-zero amount with certainty. A riskless payoff is a "charity-certain amount" or "selfcertain amount" if it is given to the American Red Cross or to the participant, respectively. In other words, participants face four types of binary decisions that vary according to the involved payoffs - \{self lottery, charity lottery $\}$ X \{self-certain amount, charity-certain amount .

Notice that participants do not face tradeoffs between payoffs for themselves and the charity when deciding between: (i) self lotteries and self-certain amounts, or (ii) charity lotteries and charity-certain amounts. In this no self-charity tradeoff context, excuses not to give are irrelevant as participants never decide whether or not to give - i.e., they cannot give in (i) or are forced to give in (ii). By contrast, participants always face tradeoffs between payoffs for themselves and the charity when deciding between: (iii) self lotteries and charity-certain amounts, or (iv) charity lotteries and self-certain amounts. In this self-charity tradeoff context, excuses not to give may be relevant. Changes in responses to risk across these contexts can thus exhibit the extent to which excuse-driven risk preferences influence charitable giving decisions.

Figure 1 shows the main results of my study by plotting how lottery valuations change as the probability $P$ of the non-zero payment increases, i.e., as risk decreases. For ease of comparison, note that the lottery valuations are scaled as percentages of the corresponding riskless lottery valuations. In the no self-charity tradeoff context, participants' responses to risk in self lotteries and charity lotteries are nearly indistinguishable. From $P=1$ to $P=0.5$, or in response to $50 \%$ risk of a zero-dollar outcome, participants reduce their valuations by about $50 \%$ for both self lotteries and charity lotteries. These equivalent responses likely result in part from a normalization, detailed later in the design, that ensures participants are indifferent between the nonzero payoffs in the self lotteries and charity lotteries. Absent this normalization, different

\footnotetext{
${ }^{7}$ In this study, a charity lottery does not involve (any chance of) payoffs to the participants. This is different than incentivizing charitable giving by entering donors into a lottery that may financially benefit themselves, such as in Landry et al. (2006).
} 
responses to risk in self lotteries and charity lotteries may have resulted from participants valuing money for themselves and the charity differently. While an emerging literature considers how individuals' responses to risk may differ over their own money and others' money, this is the first study, to my knowledge, to show equivalent responses to risk in self lotteries and charity lotteries when corresponding payoffs are normalized. ${ }^{8}$

In the self-charity tradeoff context, by contrast, participants' responses to self risk and charity risk diverge. Consistent with excuse-driven risk preferences, participants act both more averse to charity risk and less averse to self risk. In response to $50 \%$ risk, participants reduce their valuations by only $40 \%$ for self lotteries but by $60 \%$ for charity lotteries. The most stark findings, however, occur with the introduction of even small risk. From $P=1$ to $P=0.95$, or in response to only $5 \%$ risk of a zero-dollar outcome, participants' valuations for charity lotteries decrease by $32 \%$ in the self-charity tradeoff context. The reduction is four times larger than the corresponding $8 \%$ decrease in the no self-charity tradeoff context. That is, participants appear to overweight the possibility that charity lotteries yield zero-dollar payoffs, using it as an excuse to choose self certain-amounts over charity lotteries.

Figure 1: Preview of Results

No Self-Charity Tradeoff

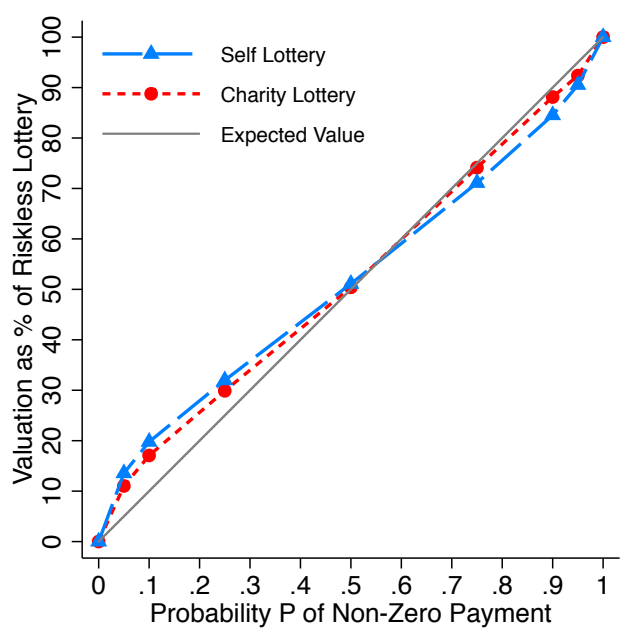

Self-Charity Tradeoff

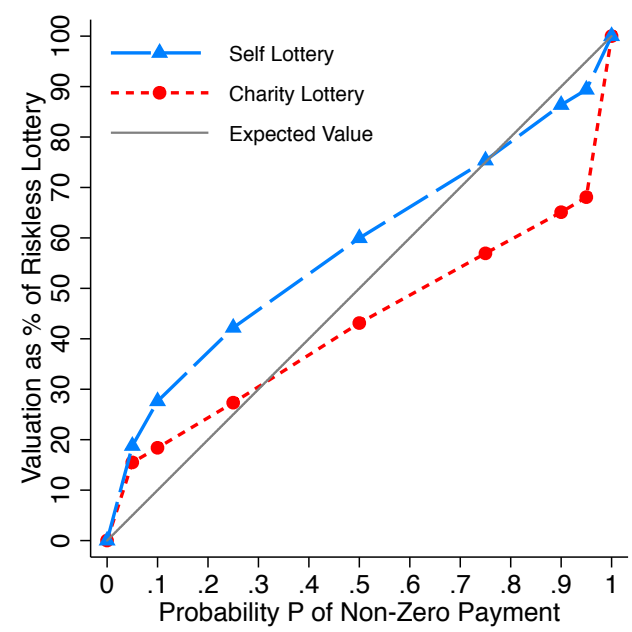

I infer from the observed treatment effects that individuals exhibit excuse-driven risk preferences. By exploiting the within-subject design of this study, additional results provide evidence for excuse-driven types of participants and hence contribute to limiting the scope for non-excusedriven explanations. First, participants who appear more selfish in riskless decisions are more

\footnotetext{
${ }^{8}$ For instance, related literature includes (Andersson et al., 2013, 2014; Bolton and Ockenfels, 2010; Brennan et al., 2008; Chakravarty et al., 2011; Eriksen et al., 2014; Güth et al., 2008). More specific to the charitable giving domain, although not risk, Exley and Terry (2015) and Bernheim and Exley (2015) show that behavioral motivations, involving reference-dependent behavior or norms, differ when earning money for oneself as opposed to for a charity.
} 
likely to also exhibit excuse-driven risk preferences in risky decisions. Second, participants with excuse-driven risk preferences are more likely to engage in other excuse behavior in a separate incentivized "moral wiggle room" task, as developed in Dana et al. (2007). While excuse-driven risk preferences involve unambiguously selfish decisions - by choosing self payoffs over charity payoffs more often - excuse-driven behavior in the moral wiggle room task involves avoiding information on whether or not decisions are selfish.

In an additional study, I test whether my results are more broadly relevant to prosocial behavior, as opposed to just charitable giving. I find strong evidence for excuse-driven risk preferences when participants decide between payoffs for themselves and payoffs for another study participant, as opposed to payoffs for a charity.

This paper proceeds as follows. Section 2 overviews the predictions according to the channels through which risk influences giving, Section 3 details the experimental design, Section 4 describes the results, and Section 5 concludes by highlighting further avenues for research.

\section{Predictions}

To determine through which channels risk influences charitable giving decisions, I elicit participants' valuations of various self lotteries and charity lotteries. Participants receive the outcomes of self lotteries; the American Red Cross (ARC) receives the outcomes of charity lotteries. A "self lottery," denoted by $P^{s}$, yields $\$ 10$ for a participant with probability $P$ and $\$ 0$ for a participant with probability $1-P$. A "charity lottery," denoted by $P^{c}$, yields $\$ \mathrm{X}$ for the charity with probability $P$ and $\$ 0$ for the charity with probability $1-P$. To ensure that charity lotteries are comparable to self lotteries, I determine participant-specific X values such that participants are indifferent between themselves receiving $\$ 10$ with certainty and the charity receiving $\$ \mathrm{X}$ with certainty. In other words, if $(U, V)$ represents a bundle where a participant receives $\$ \mathrm{U}$ and the charity receives $\$ \mathrm{~V}$, then this study will yield valuations for:

$$
\begin{aligned}
& \underbrace{P(10,0)+(1-P)(0,0)}_{P^{s}: \text { self lottery with probability } P} \quad \text { and } \underbrace{P(0, X)+(1-P)(0,0)}_{\text {where }} \\
& (10,0) \sim(0, X), \text { and } P \in\{0.05,0.1,0.25,0.5,0.75,0.9,0.95\} .
\end{aligned}
$$

Valuations of self lotteries are denoted as $Y^{j}\left(P^{s}\right)$, and valuations of charity lotteries are denoted as $Y^{j}\left(P^{c}\right)$. The superscript $j$ indicates whether lottery valuations are self-dollar valuations $(j=s)$ or charity-dollar valuations $(j=c)$. Self-dollar valuations are in dollars given to participants, and charity-dollar valuations are in dollars given to the charity. The resulting four types of lottery valuations, summarized in Table 1 and explained below, allow me to distinguish 
Table 1: Types of Lottery Valuations Resulting from Binary Decisions

\begin{tabular}{|c|c|c|}
\hline Self Lottery & $\begin{array}{c}\text { Self-Certain } \\
\text { Amount }\end{array}$ & $\begin{array}{c}\text { Charity-Certain } \\
\text { Amount }\end{array}$ \\
\hline Charity Lottery & $Y^{s}\left(P^{s}\right)$ & $Y^{c}\left(P^{s}\right)$ \\
\hline \multicolumn{2}{|c|}{ No Self-Charity Tradeoff Context } \\
Self-Charity Tradeoff Context
\end{tabular}

between three channels through which risk may influence giving.

In the no self-charity tradeoff context, valuations result from decisions involving no tradeoffs between payoffs for the participants and the charity. $Y^{s}\left(P^{s}\right)$ is the valuation such that participants are indifferent between themselves receiving $\$ Y^{s}\left(P^{s}\right)$ with certainty and themselves receiving the outcome of $P^{s} . Y^{c}\left(P^{c}\right)$ is the valuation such that participants are indifferent between the charity receiving $\$ Y^{c}\left(P^{c}\right)$ with certainty and the charity receiving the outcome of $P^{c}$. In the self-charity tradeoff context, valuations result from decisions involving tradeoffs between payoffs for the participants and the charity. $Y^{c}\left(P^{s}\right)$ is the valuation such that participants are indifferent between the charity receiving $\$ Y^{c}\left(P^{s}\right)$ with certainty and themselves receiving the outcome of $P^{s}$. $Y^{s}\left(P^{c}\right)$ is the valuation such that participants are indifferent between themselves receiving $\$ Y^{s}\left(P^{c}\right)$ with certainty and the charity receiving the outcome of $P^{c}$.

Since self-dollar valuations and charity-dollar valuations are elicited in different units, I consider valuations scaled as a percentage of the riskless lottery valuation. Self-dollar valuations $\left(Y^{s}\left(P^{s}\right)\right.$ or $\left.Y^{s}\left(P^{c}\right)\right)$ are scaled as percentages of $\$ 10$ being given to the participants. Charitydollar valuations $\left(Y^{c}\left(P^{c}\right)\right.$ or $\left.Y^{c}\left(P^{s}\right)\right)$ are scaled as percentages of $\$ \mathrm{X}$ being given to the charity. In the following predictions and discussion of my results, I assume linear utility in payoffs as doing so allows for such rescaling. However, my results are robust to interpretations that do not rely on this rescaling. ${ }^{9}$

Since participant-specific $\mathrm{X}$ values imply $(10,0) \sim(0, X)$, several models imply that participants should be indifferent between charity lotteries and self lotteries as they merely introduce the same $1-P$ probability of a $\$ 0$ outcome. That is:

$$
\underbrace{P(10,0)+(1-P)(0,0)}_{P^{s}: \text { self lottery with probability } P} \sim \underbrace{P(0, X)+(1-P)(0,0)}_{P^{c}: \text { charity lottery for probability } P}, \quad \forall P .
$$

For instance, this indifference is directly implied by the independence axiom, as in von Neumann-Morgenstern expected utility, and corresponds with what I define as standard risk preferences.

\footnotetext{
${ }^{9}$ See footnote 19 for more complete discussion in light of my empirical findings.
} 
Prediction 1 (Standard Risk Preferences) All else equal, if participants have standard risk preferences for some probability $P$, then

$$
Y^{s}\left(P^{s}\right)=Y^{c}\left(P^{s}\right)=Y^{c}\left(P^{c}\right)=Y^{s}\left(P^{c}\right)
$$

By contrast, if participants have what I define as charity-specific risk preferences, the indifference shown in relation 1 may not hold. For instance, in his theory of good intentions, Niehaus (2014) proposes that individuals may receive a "warm glow" or good feeling from thinking they did good. In some cases, such warm glow giving could cause participants to hold optimistic beliefs about the impact of their donations and respond less to different charity risk levels. More generally, charity-specific risk preferences may result if participants' risk preferences or behavioral responses to risk differ for self payoffs and charity payoffs.

Prediction 2 (Charity-Specific Risk Preferences) All else equal, if participants have charityspecific risk preferences for some probability $P$, then

$$
Y^{s}\left(P^{s}\right)=Y^{c}\left(P^{s}\right) \neq Y^{c}\left(P^{c}\right)=Y^{s}\left(P^{c}\right)
$$

By contrast, excuse-driven risk preferences allow for the possibility that the same charity lottery or the same self lottery may be valued differently depending on whether the context permits excuses not to give. In the no self-charity tradeoff context, participants never trade off payoffs for themselves with payoffs for the charity, so excuse-driven risk preferences are not relevant. However, in the self-charity tradeoff context, participants must trade off payoffs for themselves with payoffs for the charity, so excuse-driven risk preferences would bias them towards choosing payoffs for themselves. When participants decide between charity lotteries and self-certain amounts, they may overweight the possibility that charity lotteries yield zero-dollar charity payoffs as an excuse to choose the self-certain amounts over charity lotteries. A resulting increased aversion to charity risk would yield lower charity lottery valuations relative to those in the no self-charity tradeoff context. Alternatively, when participants decide between self lotteries and charity-certain amounts, they may favor the possibility that self lotteries yield non-zero self payoffs as an excuse to choose self lotteries over charity-certain amounts. A resulting decreased aversion to self risk would yield higher self lottery valuations relative to those in the no self-charity tradeoff context.

Prediction 3 (Excuse-Driven Risk Preferences) All else equal, if participants have excusedriven risk preferences for some probability $P$, then

$$
\begin{gathered}
Y^{s}\left(P^{s}\right)=Y^{c}\left(P^{c}\right) \\
\text { but } \\
Y^{c}\left(P^{s}\right)>Y^{s}\left(P^{s}\right) \text { and } Y^{c}\left(P^{c}\right)>Y^{s}\left(P^{c}\right) .
\end{gathered}
$$




\section{Data and Design}

There are two versions of my study. While Section 3.1 highlights my main study that involves charitable giving decisions, Section 3.2 details a modified version of the study that involves giving to another participant in the study, as opposed to a charity.

\subsection{Charitable Giving Study}

From November 2013 - January 2014, I recruited one-hundred undergraduate students to participate in one of five study sessions via the Stanford Economics Research Laboratory. Each study session adhered to the following design.

After participants listen to instructions and correctly answer several understanding questions, they complete thirty price lists. ${ }^{10}$ Each price list involves a series of binary decisions, from which one randomly selected decision is implemented for payments and added to their minimum participation fee of $\$ 20 .{ }^{11}$ After participants complete these price lists, they answer several followup questions, which include demographic questions and moral wiggle room questions described later (see Section 4.3). Participants are then paid in cash and exit the study. All decisions in this study remain anonymous. Participants complete this study on laptops, via an online survey platform called Qualtrics, in the Stanford Economics Research Laboratory.

Participants first complete a "normalization" price list that determines participant-specific $\mathrm{X}$ values such that they are indifferent between $\$ 10$ for themselves and $\$ \mathrm{X}$ for the charity. Participants are unaware that their choices in the normalization price list determine the non-zero payoff they will later face in decisions involving charity lotteries. Instead, in the normalization price list, they are just asked to make sixteen binary decisions between two Options (A and B). ${ }^{12}$ Option A always involves the participants receiving $\$ 10$ with certainty. However, as they proceed down the sixteen rows of the price list, Option B increases from the charity receiving $\$ 0, \$ 2, \ldots$, to $\$ 30$ with certainty. See Appendix A.1 for a screenshot of the normalization price list.

From participants' decisions in the normalization price list, I estimate participant-specific X values as follows. Assume a participant switches from choosing Option A to Option B on the $i^{\text {th }}$ row, and that this corresponds to the charity receiving $\$ B_{i}$. It then follows that $B_{i-1} \leq X \leq B_{i}$,

\footnotetext{
${ }^{10}$ If they incorrectly answer a question, they are redirected to answer it again until they provide the correct answer. At this time, they may also ask any questions to the study leader.

${ }^{11}$ Implementing payoffs from one row of multiple price lists (MPLs) is a common experimental procedure that is incentive compatible if one assumes sufficiently narrow framing, or as discussed in Azrielli et al. (2014), if one assumes dominated lotteries are never chosen. Also, if one considers this payment mechanism a compound lottery, then my observed treatment effects are difficult to rationalize since any given decision has less than a 0.2 percent chance of being implemented.

${ }^{12}$ Nonetheless, imagine that participants could forecast this feature of the study. Unless a participant derives disutility from the charity receiving higher donations, there is no motivation to make choices such that $\mathrm{X}$ would be underestimated. On the other hand, if participants overestimate $\mathrm{X}$, then this would bias my results against being able to find evidence for excuse-driven risk preferences, as discussed in footnote 13.
} 
and I estimate $\mathrm{X}$ as its upper bound of $B_{i}$. I choose the upper bound as overestimations of $\mathrm{X}$ bias my results against finding evidence for excuse-driven risk preferences. ${ }^{13}$

There are two cases where X cannot be accurately estimated in my data. The first case involves "multiple switch points." Although Option A is fixed and Option B increases as a participant proceeds down the rows of the price list, a participant may choose Option B on row $i$ but may not choose a higher valued Option $\mathrm{B}$ on some later row $i+j$, implying a violation of monotonicity in preferences. Only one participant has multiple switch points in the normalization price list, and this participant will be excluded from the remaining analysis. The second case involves "censored X values," which occur if a participant never chooses Option B, or always chooses $\$ 10$ for themselves over the charity receiving any amount up to $\$ 30$. Forty-two participants (out of the one-hundred participants) have censored $\mathrm{X}$ values. This occurrence is comparable to Engel (2011)'s meta study finding that $36 \%$ of dictators never give any positive amount - which normally could be as little as $\$ 1$ - to their recipients in dictator games. My main results exclude participants with censored $\mathrm{X}$ values, although my results are robust to including this group by assuming their $\mathrm{X}$ values are equal to their lower bound of $\$ 30$.

Therefore, my main results are likely most relevant among a population interested in donating to the charity in this study, i.e., the American Red Cross. This explanation is bolstered by participants' decisions in a second price list that serves as a buffer between the normalization task and valuation tasks. Participants complete the second price list immediately after the normalization price list, and it only differs by replacing the $\$ 10$ payoff for participants in Option A with a $\$ 5$ payoff for participants. In return, I find that $69 \%$ of participants with censored X values are also unwilling to give up $\$ 5$ for themselves in order for the charity to receive $\$ 30$. Even among participants without censored X, Figure 2 shows that $87 \%$ of these participants have X values that exceed $\$ 10$ - i.e., they are only willing to give up $\$ 10$ for themselves in exchange for the charity receiving more than $\$ 10$. The average $\mathrm{X}$ value is correspondingly $\$ 17.30 .{ }^{14}$

After completing the first and second price lists, participants complete twenty-eight price lists that provide data on their lottery valuations. In each of the "valuation" price lists, participants make twenty-one binary decisions between two Options (A and B). In a given price list, Option $\mathrm{A}$ is constant across all rows, and always involves a self lottery or a charity lottery. Recall that self lotteries yield $\$ 10$ for the participants with probability $P$ and $\$ 0$ otherwise, while charity lotteries yield $\$ \mathrm{X}$ for the charity with probability $P$ and $\$ 0$ otherwise. On the other hand, Option

\footnotetext{
${ }^{13}$ In particular, excuse-driven risk preferences imply that participants act more averse to risk in charity lotteries, or that valuations of charity lotteries significantly decrease as the probability $P$ decreases. My estimation of $\mathrm{X}$ assumes that participants value the charity lottery with $P=1$ at $\$ 10$ for themselves. If they instead valued the charity lottery with $P=1$ higher than $\$ 10$ for themselves, then the drop in their valuations of charity lotteries as $P$ decreases would be underestimated.

${ }^{14} 3 \%$ of the participants seem oddly "too prosocial," as their X values are $\$ 6$. In this case, a seemingly dominant option would be for them to choose $\$ 10$ for themselves, as they could then donate $\$ 6$ to the charity (after the study) and still have $\$ 4$ remaining for themselves. Such decisions could be explained, however, from them desiring to appear prosocial to the experimenter or having high transaction costs of donating to the charity.
} 
Figure 2: Distribution of $\mathrm{X}$



Each bar shows the percent of the participants with a given $\mathrm{X}$ value, where $\mathrm{X}$ is estimated for each participants such that they are indifferent between themselves receiving $\$ 10$ and the charity receiving $\$ \mathrm{X}$, or $(10,0) \sim$ $(0, X)$. The results include data for the 57 participants in my main subsample (i.e., excludes participants with $\mathrm{X}$ values that were censored or resulted from decisions with multiple switch points).

B always involves either a self-certain amount or a charity-certain amount that increases as they proceed down the rows of the price list. Self-certain amounts yield $\$ 0, \$ 0.50, \ldots$, or $\$ 10$ to the participants with certainty, while charity-certain amounts yield $\$ 0, \$ \frac{X}{20}, \ldots$, or $\$ \mathrm{X}$ to the charity with certainty.

Notice that the payoff recipients for the lotteries and certain amounts correspond with the desired two-by-two design previously displayed in Table 1: \{self lottery, charity lottery\} X \{selfcertain amount, charity-certain amount\}. There are correspondingly four "blocks," each with 7 price lists. Price lists within a block only differ according to the probability $P$ involved in the lottery, where $P \in\{0.95,0.90,0.75,0.50,0.25,0.10,0.05\}$. Participants complete all price lists in one block, then all price lists in another block, and so on. Blocks are presented in a randomly determined order for each participant. Appendices A.3 - A.6 show example price lists from each block.

From participants' decisions in a valuation price list, I estimate their corresponding lottery valuations as follows. Imagine that participants switch from choosing a lottery in Option A to some certain amount in Option B on the $i^{t h}$ row. Since the certain amount in Option B always increases as participants proceed down the rows, their valuations fall between $B_{i-1}$ and $B_{i}$. I then follow previous literature by estimating their valuations as the midpoint - i.e., $\frac{B_{i-1}+B_{i}}{2} .{ }^{15}$

\footnotetext{
${ }^{15} \mathrm{I}$ do not choose the midpoint in my previous estimation of $\mathrm{X}$, since as explained in footnote 13 , choosing the upper bound of X biases my results against finding evidence for excuse-driven risk preferences. Since participants
} 
As with the normalization price lists, decisions from the valuation price lists may involve censoring problems and/or multiple switch points. While censoring remains a concern for participants with censored X values, it turns out not to be a concern for participants without censored $\mathrm{X}$ values. ${ }^{16}$ Multiple switch points occur for less than $1 \%$ of the valuation price lists, which is significantly less than the typical $15 \%$ observed in the literature. ${ }^{17}$ My main analysis will follow Meier and Sprenger (2010), among many others, by including these observations under the assumption that their first switch point is their true switch point. However, my results are also robust to excluding any participant or observation that involves multiple switch points in the valuation price lists.

\subsection{Partner Study}

To test the robustness of my results to prosocial behavior more generally, I replicate my study in an environment where participants make decisions between payoffs for themselves and payoffs for another participant in the study. In March of 2014, I recruited forty-four undergraduate students to participate in one of two study sessions via the Stanford Economics Research Laboratory. The design features of this study only differ from Section 3.1 in two ways. First, I assign half of the participants to the Left Group and the remaining half of the participants to the Right Group, according to the side of the lab in which they are seated. Instead of one randomly selected decision being implemented for each participant, only one randomly selected decision is implemented for each participant in the randomly selected group (i.e., the Left Group or the Right Group).

Second, instead of choosing between self payoffs and charity payoffs, participants choose between self payoffs and partner payoffs. Partner payoffs involve payoffs given to participants' partners, who are randomly and anonymously selected to be another participant not in their group (i.e., participants in the Left Group have partners in the Right Group, and vice versa). When participants make decisions involving their partner, note that these decisions should not be influenced by realized reciprocity since only a decision made by a participant or a decision made by a participant's partner will be implemented.

face the estimated X in the study, I cannot consider other estimations of X. However, I can consider other estimations of the lottery valuations, and my results are robust to instead considering the upper bound.

${ }^{16}$ In over $96 \%$ of the valuation price lists, participants without censored X values switch from choosing Option A to Option B. In the remaining less than $4 \%$ of cases, participants always choose Option A and I assume the valuation is then the maximum certain amount offered. This approach can be explained by the following example. Consider a participant who always chooses a self lottery (say, $\$ 10$ for themselves with $95 \%$ chance and $\$ 0$ otherwise) over any charity certain amount (up to $\$ \mathrm{X}$ for the charity). Then, the self lottery valuation is weakly greater than $\$ \mathrm{X}$ for the charity. Monotonic preferences, however, imply the participant values the self lottery weakly less than $\$ 10$ for themselves, and hence weakly less than $\$ \mathrm{X}$ for the charity (from the normalization task). It thus follows that the self lottery valuation is $\$ \mathrm{X}$ for the charity.

${ }^{17}$ This lower occurrence of multiple switch points likely results from my design following Andreoni and Sprenger (2011) by providing clarifying instructions before price lists and preselecting Option A in the first row of each price lists over the $\$ 0$ certain amount in Option B (see Appendix A for corresponding screenshots of instructions). 
As before, there are two cases where $\mathrm{X}$ cannot be accurately estimated in my data. The first case involves two participants with multiple switch points in the normalization price list. These two participants will be excluded from the remaining analysis. The second case involves thirteen participants with censored $\mathrm{X}$ values, which occur if a participant never chooses Option B, or always chooses $\$ 10$ for themselves over their partner receiving any amount up to $\$ 30$. As in the charity treatment, the main partner results exclude participants with censored $\mathrm{X}$ values, although they are robust to including this group by assuming their $\mathrm{X}$ values are equal to their lower bound of $\$ 30$. Figure 3 shows that all of the participants without censored $\mathrm{X}$ values prefer $\$ 10$ for themselves over $\$ 10$ for their partner. While the average $\mathrm{X}$ value is slightly higher than in the charity treatment, both treatments have a median $\mathrm{X}$ value of $\$ 16$.

Figure 3: Distribution of X in Partner Study

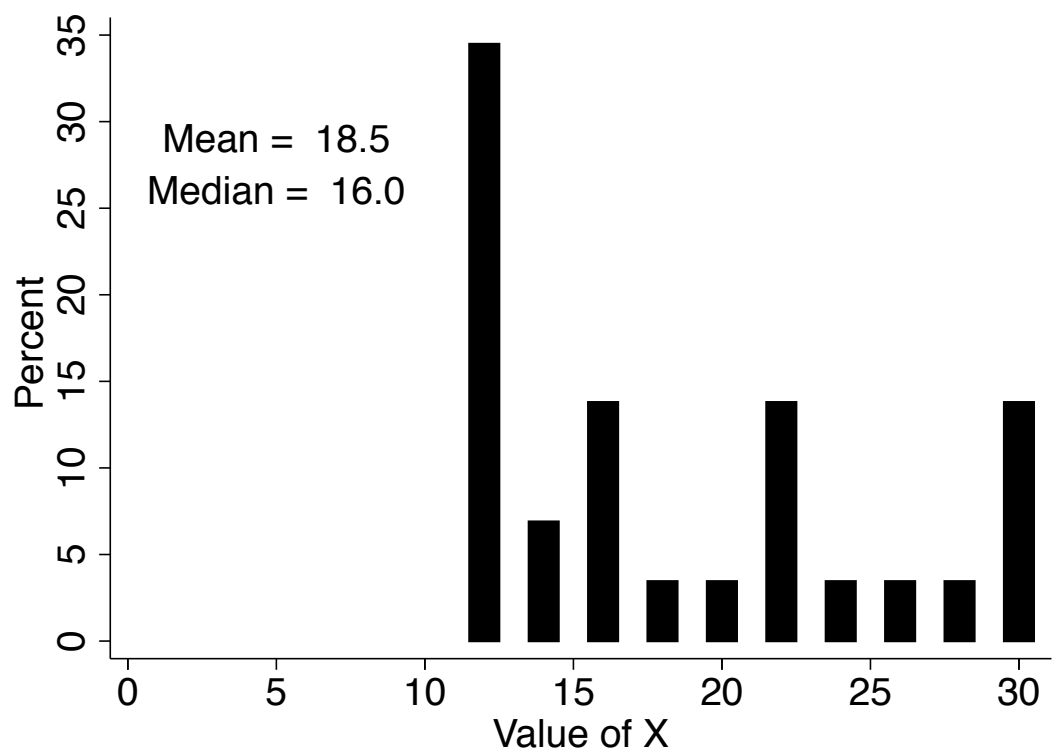

Each bar shows the percent of the participants with a given $\mathrm{X}$ value, where $\mathrm{X}$ is estimated for each participants such that they are indifferent between themselves receiving $\$ 10$ and their partner receiving $\$ \mathrm{X}$, or $(10,0) \sim$ $(0, X)$. The results include data for the 29 participants in my main subsample (i.e., excludes participants with $\mathrm{X}$ values that were censored or resulted from decisions with multiple switch points).

\section{Results}

Section 4.1 provides evidence against charity-specific risk preferences by documenting similar responses to self risk and charity risk in the no self-charity tradeoff context. Section 4.2 supports excuse-driven risk preferences by detailing the pattern of divergence between participants' responses to self risk and charity risk in the self-charity tradeoff context. Section 4.3 considers heterogeneous effects and provides support for the existence of excuse-driven "types" of participants. Section 4.4 confirms the robustness of the results in the partner study. 


\subsection{Evidence against Charity-Specific Risk Preferences}

The left panel of Figure 1 plots the self lottery and charity lottery valuations in the no self-charity tradeoff context. With respect to participants' valuations of self lotteries, they appear more risk seeking with low probabilities (high risk) and risk averse with high probabilities (low risk). The corresponding inverse-S pattern of valuations as a function of risk is a standard empirical finding and replicates results from previous studies on risk. For instance, as shown in Appendix Figure B.1, estimates of cumulative prospect theory parameters for the self lottery data are very similar to previous studies. ${ }^{18}$

With respect to the comparison of responses to risk in self and charity payoffs, Appendix Tables B.1 and B.2 confirm that the differences between valuations for charity lotteries and self lotteries are not statistically different on average nor do they exceed more than a few percentage points at any given probability level. These results also hold on a decision level; when considering an individuals' self and charity lottery valuations for a given probability, $42 \%$ are exactly the same, and $83 \%$ differ by no more than ten percentage points.

\subsection{Evidence for Excuse-Driven Risk Preferences}

The right panel of Figure 1 plots the self lottery and charity lottery valuations in the self-charity tradeoff context. Participants' responses to charity risk and self risk now diverge by fifteen percentage points on average. Appendix Tables B.3 and B.4 confirm this difference overall and at the various probability levels. These results also hold on a decision level; when considering an individuals' self and charity lottery valuations for a given risk level, $78 \%$ are not the same, and $54 \%$ differ by more than ten percentage points.

To show that the observed divergence is consistent with excuse-driven risk preferences, consider the difference-in-differences estimates from Equation 2. The dependent variable $Y_{l i}$ is an individual $i$ 's valuation of a particular lottery $l$. While the coefficient on charity li $_{\text {captures }}$ whether or not there are significant differences between charity and self lottery valuations in the no self-charity tradeoff context, the coefficients on tradeoff $f_{l i}$ and charity*tradeoff ${ }_{l i}$ indicate the extent to which there are excuse-driven risk preferences.

$$
\begin{aligned}
Y_{l i} & =\beta_{0}+\beta_{1} \text { charity }_{l i}+\beta_{2} \text { tradeoff }_{l i}+\beta_{3} \text { charity }^{*} \text { tradeoff }_{l i} \\
& +\left(\sum_{P} \lambda_{P}+\sum_{i} \mu_{i}\right)+\epsilon_{l i}
\end{aligned}
$$

where

\footnotetext{
${ }^{18}$ This observed pattern is more broadly consistent with models that allow for curvature via probability weighting functions (Prelec, 1998) or utility functions that are concave and convex over different ranges (Holt and Laury, 2002).
} 


$$
\begin{aligned}
& Y_{l i} \equiv \text { valuation of a lottery } l \text { (as a } \% \text { of corresponding riskless lottery valuation) } \\
& \text { charity }_{l i} \equiv \text { indicator for charity lottery } \\
& \text { tradeoff } l i \text { 三 indicator for lottery being elicited in self-charity tradeoff context } \\
& \text { charity }^{*} \text { tradeoff }_{l i} \equiv \text { interaction variable of } \text { charity }_{l i} \text { and tradeoff } l i \\
& \lambda_{P} \equiv \text { probability fixed effect, } \mathrm{P} \in\{0.95,0.9,0.75,0.5,0.25,0.1\} \quad(\mathrm{P}=0.05 \text { excluded }) \\
& \mu_{i} \equiv \text { individual fixed effect (individual } i=1 \text { excluded) }
\end{aligned}
$$

Column 1 of Table 2 displays the corresponding regression results with no controls. To begin, note that the coefficient on charity $_{l i}$ is not statistically different than zero, consistent with the lack of evidence for charity-specific risk preferences. However, the coefficient on tradeoff $l i$ shows that participants' self lottery valuations are about five percentage points higher on average in the self-charity tradeoff context. Participants appear to overweight the possibility that self lotteries yield non-zero-dollar payoffs, using it as an excuse to choose self lotteries over charity certainamounts more often than their non-excuse-driven risk preferences would imply. Additionally, the sum of the coefficients on tradeoff $l i$ and charity*tradeoff ${ }_{l i}$ shows that participants' charity lottery valuations are about ten percentage points lower in the self-charity tradeoff context. Participants appear to overweight the possibility that charity lotteries yield zero-dollar payoffs, using it as an excuse to choose self certain-amounts over charity lotteries more often than their non-excusedriven risk preferences would imply.

Columns 2 - 4 confirm the robustness of the results to the inclusion of individual fixed effects regardless of whether or not observations or participants with multiple switch points are excluded, and Column 5 finds similar results with probability fixed effects. Column 6 shows that the results hold with interval regressions, where the dependent variables are the upper and lower bounds of the lottery valuations, as opposed to the midpoint of the range implied by participants' price lists decisions. While Columns 1 - 6 exclude participants with censored values of X, Column 7 shows that the results are even larger when considering Tobit regressions that include participants with censored values of $\mathrm{X}$ - i.e., individuals who are never willing to give up $\$ 10$ for themselves in exchange for the charity receiving any certain amount up to $\$ 30$. As these individuals could be considered the most selfish in this study, this larger finding could in part result from more selfish individuals being more excuse-driven. The possibility for such heterogeneous effects, or excuse-driven types of individuals, is further explored in the next section.

These results show that participants appear to use risk, regardless of whether it is charity risk or self risk, as an excuse not to give. While the charity risk results may be more similar to typical charitable giving decisions, the self risk results highlight a key advantage of the laboratory environment as they serve as an useful robustness check of excuse-driven risk preferences. For instance, contrary to the study instructions and the adhered policy of no deception in the Stanford 
Table 2: Lottery Valuations

\begin{tabular}{|c|c|c|c|c|c|c|c|}
\hline \multirow[t]{2}{*}{$\begin{array}{l}\text { Regression: } \\
\text { DV: }\end{array}$} & \multicolumn{5}{|c|}{$\begin{array}{c}\text { Ordinary Least Squares } \\
Y_{l}\end{array}$} & \multirow{2}{*}{$\begin{array}{c}\text { Interval } \\
Y_{l}^{\text {lower }} \\
Y_{l}^{\text {upper }} \\
6 \\
\end{array}$} & \multirow{2}{*}{$\begin{array}{c}\text { Tobit } \\
Y_{l} \\
\\
7 \\
\end{array}$} \\
\hline & 1 & 2 & 3 & 4 & 5 & & \\
\hline charity & $\begin{array}{c}0.06 \\
(0.82)\end{array}$ & $\begin{array}{c}0.06 \\
(0.82)\end{array}$ & $\begin{array}{c}0.25 \\
(0.88)\end{array}$ & $\begin{array}{l}-0.44 \\
(0.83)\end{array}$ & $\begin{array}{c}0.06 \\
(0.82)\end{array}$ & $\begin{array}{c}0.23 \\
(0.87)\end{array}$ & $\begin{array}{c}1.30 \\
(0.80)\end{array}$ \\
\hline tradeoff & $\begin{array}{l}5.30^{* *} \\
(2.02)\end{array}$ & $\begin{array}{l}5.30^{* *} \\
(2.02)\end{array}$ & $\begin{array}{c}5.58^{* * *} \\
(2.04)\end{array}$ & $\begin{array}{l}4.94^{* *} \\
(2.21)\end{array}$ & $\begin{array}{l}5.30^{* *} \\
(2.02)\end{array}$ & $\begin{array}{c}6.81^{* * *} \\
(2.31)\end{array}$ & $\begin{array}{c}27.50^{* * *} \\
(3.59)\end{array}$ \\
\hline charity*tradeoff & $\begin{array}{c}-15.09^{* * *} \\
(3.40)\end{array}$ & $\begin{array}{c}-15.09^{* * *} \\
(3.40)\end{array}$ & $\begin{array}{c}-15.69^{* * *} \\
(3.50)\end{array}$ & $\begin{array}{c}-14.51^{* * *} \\
(3.81)\end{array}$ & $\begin{array}{c}-15.09^{* * *} \\
(3.41)\end{array}$ & $\begin{array}{c}-16.53^{* * *} \\
(3.77)\end{array}$ & $\begin{array}{c}-47.44^{* * *} \\
(5.29)\end{array}$ \\
\hline$I(P=0.95)$ & & & & & $\begin{array}{c}70.38^{* * *} \\
(1.87)\end{array}$ & & \\
\hline$I(P=0.90)$ & & & & & $\begin{array}{c}66.32^{* * *} \\
(1.76)\end{array}$ & & \\
\hline$I(P=0.75)$ & & & & & $\begin{array}{c}54.67^{* * *} \\
(1.46)\end{array}$ & & \\
\hline$I(P=0.50)$ & & & & & $\begin{array}{c}36.44^{* * *} \\
(1.18)\end{array}$ & & \\
\hline$I(P=0.25)$ & & & & & $\begin{array}{c}18.14^{* * *} \\
(1.09)\end{array}$ & & \\
\hline$I(P=0.10)$ & & & & & $\begin{array}{c}6.01^{* * *} \\
(0.63)\end{array}$ & & \\
\hline Constant & $\begin{array}{c}51.79^{* * *} \\
(0.96)\end{array}$ & $\begin{array}{c}51.79^{* * *} \\
(0.61)\end{array}$ & $\begin{array}{c}51.89^{* * *} \\
(0.63)\end{array}$ & $\begin{array}{c}51.85^{* * *} \\
(0.62)\end{array}$ & $\begin{array}{c}15.80^{* * *} \\
(1.36)\end{array}$ & $\begin{array}{c}51.83^{* * *} \\
(0.97)\end{array}$ & $\begin{array}{c}50.50^{* * *} \\
(0.80)\end{array}$ \\
\hline Ind $\mathrm{FE}$ & no & yes & yes & yes & no & no & no \\
\hline Obs with MSP & yes & yes & no & no & yes & yes & yes \\
\hline Ind with MSP & yes & yes & yes & no & yes & yes & yes \\
\hline Censored X & no & no & no & no & no & no & yes \\
\hline Observations & 1596 & 1596 & 1576 & 1400 & 1596 & 1596 & 2772 \\
\hline Subjects & 57 & 57 & 57 & 50 & 57 & 57 & 99 \\
\hline
\end{tabular}

${ }^{*} p<0.10,{ }^{* *} p<0.05,{ }^{* * *} p<0.01$. Standard errors are clustered at the individual level and shown in parentheses. The dependent variables are lottery valuations $Y_{l}$ - i.e., self-dollar valuations of self lotteries $\left(Y^{s}\left(P^{s}\right)\right)$ or charity lotteries $\left(Y^{s}\left(P^{c}\right)\right)$, and charity-dollar valuations of self lotteries $\left(Y^{c}\left(P^{s}\right)\right)$ or charity lotteries $\left(Y^{c}\left(P^{c}\right)\right)$. Valuations in self-dollars are scaled as percentages of $\$ 10$, and valuations in charitydollars are scaled as percentages of $\$ X_{i}$. The results are from regressions of Equation 2. Probability fixed effects are shown when included, and "Ind FE" indicates whether or not individual fixed effects are included. "Obs with MSP" and "Ind with MSP" indicate whether or not observations with, or individuals that have observations with, multiple switch points are included. When observations involving multiple switch points are included, the first switch point is assumed. "Censored X" indicates whether or not participants with censored X values are included. Note that 1 participant is always excluded because their X value resulted from decisions with multiple switch points. 
Economics Research Laboratory, participants could believe that the experimenter will resolve charity lotteries or distribute outcomes of charity lotteries in a manner biased against the charity receiving its payoffs. Alternatively, participants may believe there is some additional risk in how charities will use any donations they receive. Neither of these possibilities, however, can explain why participants use self risk, not just charity risk, as an excuse not to give.

These results are robust to several other considerations as well. First, Appendix Tables B.5 and B.6 confirm these results when separately looking at charity lottery valuations or self lottery valuations. Second, Appendix Tables B.7 and B.8 provide evidence for excuse-driven risk preferences when separately considering valuations elicited in self-dollars or charity-dollars as to avoid the need to rescale valuations. ${ }^{19}$ Third, Appendix Table B.9 shows that the results are robust to the order in which participants value charity lotteries or self lotteries, and the differencein-differences estimations ease other framing effects that may arise from the multiple price list elicitations procedure. ${ }^{20}$ Fourth, similar findings are observed when considering decision level results, as shown by the fraction of lottery valuations that fall below or exceed their expected value in Appendix Figure B.2.

\subsection{Evidence for Excuse-Driven Types of Participants}

This section investigates the possibility of excuse-driven "types" of participants. ${ }^{21}$ Documenting the existence of such types may help to unify the literature on excuse-driven behavior and to limit the scope for non-excuse-driven explanations.

To begin, it is useful to note that there is an individual-level of consistency in excuse-driven behavior across lottery valuations: participants who appear to use self risk as an excuse not to give, by acting less averse to self risk in the self-charity tradeoff context, also appear to use charity risk as an excuse not to give, by acting more averse to charity risk in the self-charity tradeoff context. $^{22}$ On one extreme, Figure 4 displays the valuations for a participant without excusedriven risk preferences: this participant always responds to self risk and charity risk in the same

\footnotetext{
${ }^{19}$ By only comparing valuations in self dollars to each other, or only comparing valuations in charity dollars to each other, rescaling of valuations is not needed but I still find evidence for excuse-driven risk preferences. For self-dollar valuations, excuse-driven risk preferences are only relevant for the charity lotteries and would imply lower valuations for charity lotteries, as confirmed in Appendix Table B.7. For charity-dollar valuations, excuse-driven risk preferences are only relevant for self lotteries and would imply higher self lottery valuations, as confirmed in Appendix Table B.8.

${ }^{20}$ For instance, Castillo and Eil (2014) show that multiple price lists can cause people to act more or less averse to risk depending on the status quo, such as the fixed option in a price list. While participants may act less averse to risk since this study always fixed the risky payoff in Option A, such a level effect would be accounted for in the difference-in-differences estimations.

${ }^{21}$ Previous literature that considers whether there exists "giving types" includes De Oliveira et al. (2011); Carpenter and Myers (2010).

${ }^{22}$ Consider the difference in a participant's valuations of a lottery in the no self-charity tradeoff context and self-charity tradeoff context to indicate the extent to which their valuation of that lottery is self-serving. There is a strong positive rank correlation across nearly all pairwise comparisons of these differences.
} 
manner across both contexts. By contrast, Figure 5 displays valuations for a participant with clear excuse-driven risk preferences: this participant almost always acts less averse to self risk and more averse to charity risk in the self-charity tradeoff context. The majority of participants, without censored $\mathrm{X}$ values, appear to similarly exhibit excuse-driven risk preferences to varying degrees: for $65 \%$ of the participants, the average difference in their lottery valuations across contexts is in a self-serving direction that ranges from just under 1 to 42 percentage points.

Figure 4: Example Participant without Excuse-Driven Risk Preferences
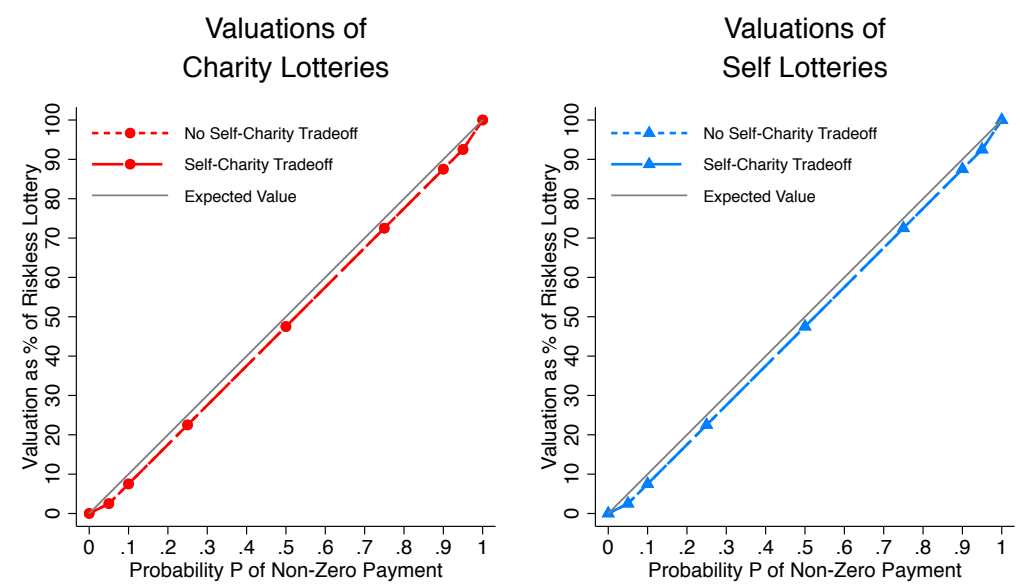

In the left panel, the no self-charity tradeoff data indicate the charity-dollar valuations of charity lotteries, $Y^{c}\left(P^{c}\right)$; the self-charity tradeoff data indicate the self-dollar valuations of charity lotteries, $Y^{s}\left(P^{c}\right)$. In the right panel, the no self-charity tradeoff data indicate the self-dollar valuations of self lotteries, $Y^{s}\left(P^{s}\right)$; the self-charity tradeoff data indicate the charity-dollar valuations of self lotteries, $Y^{c}\left(P^{s}\right)$. Valuations in selfdollars are scaled as percentages of $\$ 10$, and valuations in charity-dollars are scaled as percentages of $\$ X_{i}$. The Expected Value line indicates the expected value for a lottery given the probability $P$.

In addition to an individual-level consistency across lottery valuations, selfish participants may be more likely to exhibit excuse-driven risk preferences. In this study, participants' level of selfishness is indicated by their $\mathrm{X}$ values - i.e., how much does the charity have to receive such that they are willing to give up $\$ 10$ for themselves. To consider whether participants' $\mathrm{X}$ values correspond with the extent of their excuse-driven behavior, I interact the main treatment effects with $(X-\bar{X})$, where $\bar{X}$ is the average $\mathrm{X}$ value among the participants. As shown in Column 2 of Table 4, participants with higher $\mathrm{X}$ values have a significantly larger tendency to exhibit excuse-driven risk preferences. A one dollar increase in a participant's X value corresponds with, in self-charity tradeoff context, a $\$ 1.11$ increase in self lottery valuations and a $\$ 0.45$ decrease in their charity lottery valuations, on average.

To consider an arguably more demanding test for excuse-driven types of participants, I examine whether excuse-driven risk preferences in lottery valuations correlate with excuse-driven behavior in a separate task that replicates a "moral wiggle room" task developed in Dana et al. (2007). ${ }^{23}$ The moral wiggle room task involves two important features. First, behavior in this

\footnotetext{
${ }^{23}$ The moral wiggle room task in my study closely follows two treatments from Dana et al. (2007) - i.e., their
} 
Figure 5: Example Participant with Excuse-Driven Risk Preferences
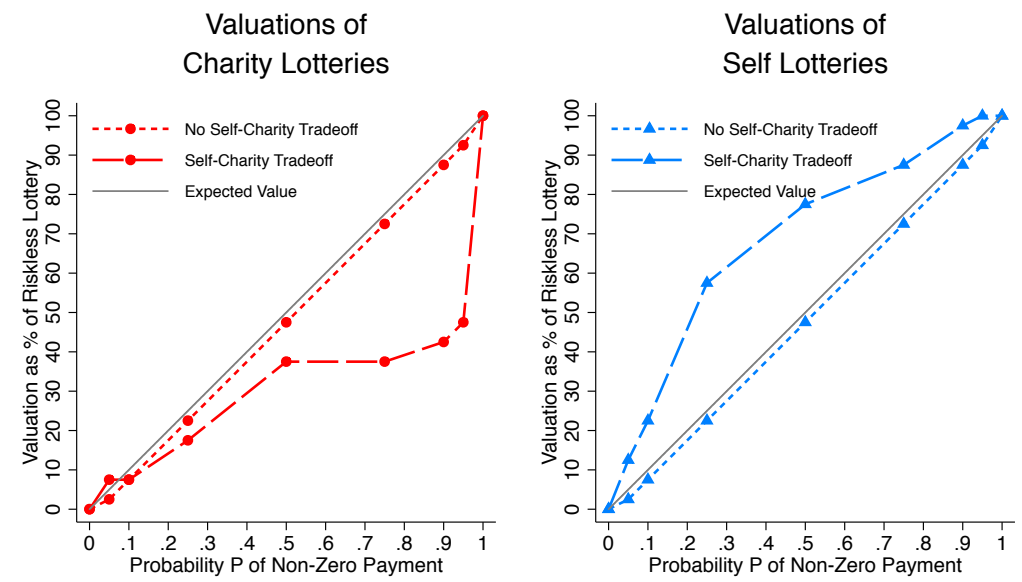

In the left panel, the no self-charity tradeoff data indicate the charity-dollar valuations of charity lotteries, $Y^{c}\left(P^{c}\right)$; the self-charity tradeoff data indicate the self-dollar valuations of charity lotteries, $Y^{s}\left(P^{c}\right)$. In the right panel, the no self-charity tradeoff data indicate the self-dollar valuations of self lotteries, $Y^{s}\left(P^{s}\right)$; the self-charity tradeoff data indicate the charity-dollar valuations of self lotteries, $Y^{c}\left(P^{s}\right)$. Valuations in selfdollars are scaled as percentages of $\$ 10$, and valuations in charity-dollars are scaled as percentages of $\$ X_{i}$. The Expected Value line indicates the expected value for a lottery given the probability $P$.

task involves a well-studied phenomenon that is believed to be excuse-driven: participants often behave more selfishly by avoiding information on whether or not their action is selfish. ${ }^{24}$ Second, excuse-driven behavior in the moral wiggle room task differs from excuse-driven risk preferences in lottery valuations, making it a useful out-of-context consideration. For instance, while excuse-driven behavior in the moral wiggle room task involves participants avoiding information on whether or not their actions are selfish, excuse-driven risk preferences occur even though participants know their actions are selfish as they choose self payoffs over charity payoffs.

Participants complete the moral wiggle room task as part of a follow-up survey at the end of the study. In order to classify excuse-driven types of participants, each participant answers three questions in this task, and one question is randomly selected to count for payments. In each question, participants choose between two options - $A$ and $B$ - that yield payoffs for themselves and payoffs for the charity (i.e., the American Red Cross). These payoffs, as shown in Table 3 , involve a bundle $(U, V)$ that corresponds with the participant receiving $\$ U$ and the charity receiving $\$ \mathrm{~V}$. In the aligned state, the options are $A:(\$ 6, \$ 5)$ and $B:(\$ 5, \$ 1)$, so $A$ yields maximum payoffs for both the participants and the charity. In the unaligned state, the options are $A:(\$ 6, \$ 1)$ and $B:(\$ 5, \$ 5)$, so $A$ yields maximum payoffs for the participant, but $B$ yields maximum payoffs for the charity.

In the first question, or choice-to-reveal question, there is an equal probability that partici-

Baseline Treatment and Hidden Information Treatment.

${ }^{24}$ In fact, Bartling et al. (2014) show that dictators get punished less for selfish decisions if they made their decision after purposely avoiding information on whether or not their action is selfish, as opposed to knowing their action is selfish. 
pants face payoffs in the unaligned state or in the aligned state. While participants are not told which state they are in, they may reveal their state, for free, before choosing between $A$ and $B$. Choosing to reveal their state allows participants to ensure their preferred payoffs for themselves and the charity. However, excuse-driven participants in the moral wiggle room task may choose not to reveal their state; in doing so, they can then choose $A$ without knowing whether or not $A$ is selfish. Studies documenting excuse-driven behavior in the moral wiggle room task typically document such avoidance leading to an increase in overall selfish behavior. ${ }^{25}$

In the second question, or revealed-unaligned-state question, participants know they are in the unaligned state and must choose between $A$ and $B$. In this case, choosing $A$ is selfish since it results in lower charity payoffs in exchange for higher self payoffs.

In the third question, or revealed-aligned-state question, participants know they are in the aligned state, and then must choose between $A$ and $B$. In this case, choosing $A$ is not selfish as it yields the highest payoffs for both the participants and the charity.

Table 3: Moral Wiggle Room Payoffs

\begin{tabular}{ccc}
\hline \hline & Unaligned State & Aligned State \\
\hline$A$ & $(6,1)$ & $(6,5)$ \\
$B$ & $(5,5)$ & $(5,1)$ \\
\hline \hline
\end{tabular}

The bundle $(U, V)$ corresponds with the participant receiving $\$ \mathrm{U}$ and the charity receiving $\$ \mathrm{~V}$.

While the aggregate results detailed in Appendix $\mathrm{C}$ provide evidence for excuse-driven behavior in the moral wiggle room task, I turn to individual level results to classify participants according to their behavior in the moral wiggle room task. Aside from one participant (out of the one-hundred), all participants are classified into one of the following three categories. ${ }^{26}$ First, $44 \%$ of the participants are selfish-types as they choose the selfish option $A$ in the revealedunaligned-state question. These participants also choose the (potentially) selfish option $A$ in the choice-to-reveal question. Second, $35 \%$ of the participants are generous-types as they choose the fair option $B$ in the revealed-unaligned-state, and indicate that they place some value on the charity payoffs in the choice-to-reveal question by choosing to reveal their state. Note that conditional on participants revealing their state in the choice-to-reveal question, I do not classify them according to their decision after the revelation; while I could classify whether participants

\footnotetext{
${ }^{25}$ In Dana et al. (2007), when their participants know they are in the unaligned state, only $26 \%$ chose the selfish option $A$. However, when their participants could choose whether or not to reveal their state, $63 \%$ of their participants in the unaligned state chose the selfish option $A$. Dana et al. (2007) explain this behavior by pointing to moral wiggle room, as half of their participants chose not to reveal their state, and among that half, $100 \%$ choose the selfish option $A$.

${ }^{26}$ The one unclassified participant chose $B$ in the choice-to-reveal state without revealing their state first. This choice guarantees themselves their lowest payoff and may or may not give the charity its lowest payoff as well.
} 
who learn they are in the unaligned-state as choosing the selfish option or not, I could not make the same classification for participants who learn they are in the aligned-state. Third, $20 \%$ of the participants are wiggler-types as they choose the fair option $B$ in the revealed-unaligned-state, but instead choose the potentially selfish option $A$ in the choice-to-reveal question after choosing not to reveal their state. That is, wiggler-types, or those susceptible to excuse-driven behavior in the moral wiggle room task, only choose the potentially selfish option when they can and do avoid free information on whether or not their choice is selfish. Among participants in my main subsample (as relevant later in Table 4), the relative representation of types changes to selfish-types (23\%), generous-types (51\%), and wiggler-types $(25 \%){ }^{27}$

Both generous-types and wiggler-types choose the fair option $B$ in the revealed-unalignedstate question. Wiggler-types, however, avoid learning their state in the choice-to-reveal question and choose the potentially selfish option $A$. If there is an individual-level of consistency in excusedriven behavior out-of-sample, then wiggler-types should be more likely to exhibit excuse-driven risk preferences than generous-types.

As shown in the third column of Table 4, wiggler-types are more likely to exhibit excusedriven risk preferences, particularly with respect to using charity risk as an excuse not to give. ${ }^{28}$ In self-charity tradeoff context, they have significantly lower charity lottery valuations and qualitatively, although not significantly, higher self lottery valuations. Similar results may be expected for selfish-types, particularly in light of the earlier finding shown in Column 2: individuals with higher X values show a greater tendency to exhibit excuse-driven behavior. While qualitatively consistent with this possibility, the binary classification of selfish-types does not significantly correspond with more excuse-driven behavior. This may in part be explained by the somewhat surprising finding of an insignificant correlation between participants' values of $\mathrm{X}$ and classifications as selfish-types. There is also an insignificant correlation between participants' values of $\mathrm{X}$ and classifications as wiggler-types, which suggests that these two characteristics may independently be important predictors of excuse-driven behavior. The fourth column of Table 4 in fact confirms that the same results hold even when there are interactions of the treatment effects with $(X-\bar{X})$, wiggler-types, and selfish-types. As a matter of interest, no significant interaction effects are observed when the treatment effects are instead interacted with an indicator for a participant's sex or stated degree of how favorably they view the American Red Cross.

\footnotetext{
${ }^{27}$ Relatively fewer selfish-types results from my main subsample excluding participants with censored X values, who also have more selfish decisions in the moral wiggle room task.

${ }^{28}$ The results are robust to excluding the one unclassified participant from the moral wiggle room task as well.
} 
Table 4: Examining Heterogeneous Effects

\begin{tabular}{|c|c|c|c|c|}
\hline \multirow{3}{*}{$\begin{array}{l}\text { Regression: } \\
\text { DV: }\end{array}$} & \multirow{2}{*}{\multicolumn{4}{|c|}{$\begin{array}{c}\text { Ordinary Least Squares } \\
Y_{l}\end{array}$}} \\
\hline & & & & \\
\hline & 1 & 2 & 3 & 4 \\
\hline charity & $\begin{array}{c}0.06 \\
(0.82)\end{array}$ & $\begin{array}{c}0.06 \\
(0.80)\end{array}$ & $\begin{array}{c}0.10 \\
(1.26)\end{array}$ & $\begin{array}{c}0.09 \\
(1.23)\end{array}$ \\
\hline tradeoff & $\begin{array}{l}5.30^{* *} \\
(2.02)\end{array}$ & $\begin{array}{c}5.30^{* * *} \\
(1.82)\end{array}$ & $\begin{array}{l}3.15 \\
(2.83)\end{array}$ & $\begin{array}{c}3.15 \\
(2.38)\end{array}$ \\
\hline charity*tradeoff & $\begin{array}{c}-15.09^{* * *} \\
(3.40)\end{array}$ & $\begin{array}{c}-15.09^{* * *} \\
(3.18)\end{array}$ & $\begin{array}{l}-9.02^{*} \\
(4.55)\end{array}$ & $\begin{array}{c}-9.02^{* *} \\
(3.90)\end{array}$ \\
\hline$(X-\bar{X})$ & & $\begin{array}{l}-0.11 \\
(0.13)\end{array}$ & & $\begin{array}{l}-0.11 \\
(0.13)\end{array}$ \\
\hline charity $^{*}(X-\bar{X})$ & & $\begin{array}{l}0.26^{*} \\
(0.13)\end{array}$ & & $\begin{array}{l}0.26^{*} \\
(0.13)\end{array}$ \\
\hline tradeoff $*(X-\bar{X})$ & & $\begin{array}{c}1.11^{* * *} \\
(0.31)\end{array}$ & & $\begin{array}{l}1.11^{* * *} \\
(0.31)\end{array}$ \\
\hline charity*tradeoff* $^{*}(X-\bar{X})$ & & $\begin{array}{c}-1.56^{* * *} \\
(0.57)\end{array}$ & & $\begin{array}{c}-1.56^{* *} \\
(0.59)\end{array}$ \\
\hline wiggler & & & $\begin{array}{l}-0.62 \\
(2.17)\end{array}$ & $\begin{array}{l}-0.62 \\
(2.21)\end{array}$ \\
\hline charity* wiggler & & & $\begin{array}{c}0.90 \\
(1.65)\end{array}$ & $\begin{array}{c}0.89 \\
(1.60)\end{array}$ \\
\hline tradeoff* wiggler & & & $\begin{array}{c}4.47 \\
(4.54)\end{array}$ & $\begin{array}{c}4.45 \\
(3.99)\end{array}$ \\
\hline charity*tradeoff*wiggler & & & $\begin{array}{c}-13.48^{* *} \\
(6.46)\end{array}$ & $\begin{array}{c}-13.45^{* *} \\
(5.28)\end{array}$ \\
\hline selfish & & & $\begin{array}{l}2.68 \\
(2.54)\end{array}$ & $\begin{array}{c}2.67 \\
(2.49)\end{array}$ \\
\hline 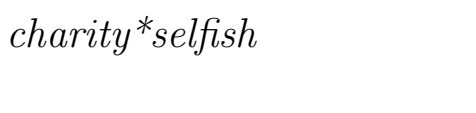 & & & $\begin{array}{l}-1.14 \\
(2.17)\end{array}$ & $\begin{array}{l}-1.13 \\
(2.10)\end{array}$ \\
\hline tradeoff* $^{*}$ selfish & & & $\begin{array}{c}4.59 \\
(5.25)\end{array}$ & $\begin{array}{c}4.63 \\
(5.09)\end{array}$ \\
\hline charity*tradeoff*selfish & & & $\begin{array}{l}-12.10 \\
(9.78)\end{array}$ & $\begin{array}{l}-12.16 \\
(10.04)\end{array}$ \\
\hline Constant & $\begin{array}{c}51.79^{* * *} \\
(0.96)\end{array}$ & $\begin{array}{c}51.79^{* * *} \\
(0.96)\end{array}$ & $\begin{array}{c}51.33^{* * *} \\
(1.30)\end{array}$ & $\begin{array}{c}51.33^{* * *} \\
(1.30)\end{array}$ \\
\hline Observations & 1596 & 1596 & 1596 & 1596 \\
\hline Subjects & 57 & 57 & 57 & 57 \\
\hline
\end{tabular}

${ }^{*} p<0.10,{ }^{* *} p<0.05,{ }^{* * *} p<0.01$. Standard errors are clustered at the individual level and shown in parentheses. The dependent variables are lottery valuations $Y_{l}$ - i.e., self-dollar valuations of self lotteries $\left(Y^{s}\left(P^{s}\right)\right)$ or charity lotteries $\left(Y^{s}\left(P^{c}\right)\right)$, and charity-dollar valuations of self lotteries $\left(Y^{c}\left(P^{s}\right)\right)$ or charity lotteries $\left(Y^{c}\left(P^{c}\right)\right)$. Valuations in self-dollars are scaled as percentages of $\$ 10$, and valuations in charity-dollars are scaled as percentages of $\$ X_{i}$. The results are from regressions of Equation 2 modified to include the shown interactions. $(X-\bar{X})$ is a participant's $\mathrm{X}$ minus the average $\mathrm{X}$. selfish is an indicator for choosing $A$ in the revealed-unaligned state. wiggler is an indicator for choosing $B$ in the revealed-unaligned-state but $A$ in the choice-to-reveal question after choosing not to reveal their state. For observations involving multiple switch points, the first switch point is assumed. Participants with censored $\mathrm{X}$ values or $\mathrm{X}$ values that resulted from decisions with multiple switch points are excluded. 


\subsection{Replication of Results in Partner Study}

In the partner study, payoffs benefit another participant in the lab as opposed to the charity. Results may therefore differ from the above discussed charity study due to several reasons perhaps most notably if excuse-driven behavior is only relevant to charitable giving and not prosocial behavior more broadly. Additionally, while the partner version eliminates differences in how payments to oneself and others are being distributed, it also introduces role-uncertainty (Iriberri and Rey-Biel, 2011) as participants do not know if their decisions or their partners' decisions will be implemented for payment.

As shown in Figure 6 and Appendix Table B.10, evidence for excuse-driven risk preferences is similar, and if anything, larger in the partner study. In the no self-partner tradeoff context, participants respond very similarly to risk. By contrast, in the self-partner tradeoff context, participants act more averse to partner risk and less averse to self risk. Table 5 provides evidence for excuse-driven risk preferences when pooling data from the charity study and partner study, and as shown in Column 2, finds qualitatively but not significantly larger evidence for excusedriven risk preferences in the partner study. Moreover, as shown in Columns 3 and 4 of Table 5 , it remains true that participants with higher values of $\mathrm{X}$ are more likely to exhibit a stronger tendency for excuse-driven behavior.

Figure 6: Lottery Valuations in Partner Study

No Self-Partner Tradeoff

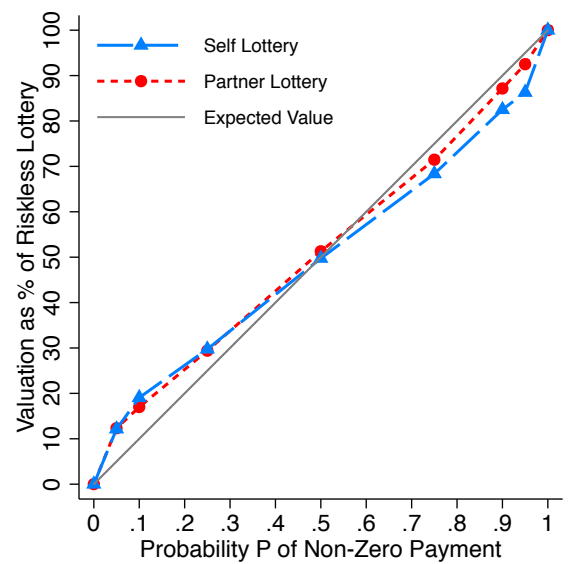

Self-Partner Tradeoff



In the left panel, the estimates are valuations in the no self-partner tradeoff context: the self lottery data indicate the self-dollar valuations of self lotteries, $Y^{s}\left(P^{s}\right)$; the partner lottery data indicate the partner dollar valuations of partner lotteries, $Y^{p}\left(P^{p}\right)$. In the right panel, the estimates are valuations in the self-partner tradeoff context: the self lottery data indicate the partner dollar valuations of self lotteries, $Y^{p}\left(P^{s}\right)$; the partner lottery data indicate the self-dollar valuations of partner lotteries, $Y^{s}\left(P^{p}\right)$. Valuations in self-dollars are scaled as percentages of $\$ 10$, and valuations in partner-dollars are scaled as percentages of $\$ \mathrm{X}$. The Expected Value line indicates the expected value for a lottery given the probability $P$. The results include data for the 29 participants in my main subsample (i.e., excludes participants with $\mathrm{X}$ values that were censored or resulted from decisions with multiple switch points). For observations involving multiple switch points, the first switch point is assumed. 
Table 5: Lottery Valuations in Charity Study and Partner Study

\begin{tabular}{|c|c|c|c|c|}
\hline \multirow[t]{2}{*}{$\begin{array}{l}\text { Regression: } \\
\text { DV: }\end{array}$} & \multicolumn{4}{|c|}{$\begin{array}{c}\text { Ordinary Least Squares } \\
Y_{l}\end{array}$} \\
\hline & 1 & 2 & 3 & 4 \\
\hline other & $\begin{array}{c}0.68 \\
(0.69)\end{array}$ & $\begin{array}{c}0.06 \\
(0.82)\end{array}$ & $\begin{array}{c}0.68 \\
(0.69)\end{array}$ & $\begin{array}{c}0.10 \\
(0.83)\end{array}$ \\
\hline tradeoff & $\begin{array}{l}6.94^{* * *} \\
(1.77)\end{array}$ & $\begin{array}{l}5.30^{* *} \\
(2.01)\end{array}$ & $\begin{array}{c}6.94^{* * *} \\
(1.59)\end{array}$ & $\begin{array}{l}5.77^{* * *} \\
(1.85)\end{array}$ \\
\hline other ${ }^{*}$ tradeoff & $\begin{array}{c}-17.60^{* * *} \\
(2.87)\end{array}$ & $\begin{array}{c}-15.09^{* * *} \\
(3.39)\end{array}$ & $\begin{array}{c}-17.60^{* * *} \\
(2.62)\end{array}$ & $\begin{array}{c}-15.80^{* * *} \\
\quad(3.21)\end{array}$ \\
\hline partner-study & & $\begin{array}{l}-2.10 \\
(1.70)\end{array}$ & & $\begin{array}{l}-2.18 \\
(1.70)\end{array}$ \\
\hline other ${ }^{*}$ partner-study & & $\begin{array}{c}1.84 \\
(1.47)\end{array}$ & & $\begin{array}{l}1.72 \\
(1.54)\end{array}$ \\
\hline tradeoff*partner-study & & $\begin{array}{c}4.87 \\
(3.92)\end{array}$ & & $\begin{array}{c}3.48 \\
(3.49)\end{array}$ \\
\hline other*tradeoff* partner-study & & $\begin{array}{l}-7.44 \\
(6.20)\end{array}$ & & $\begin{array}{l}-5.34 \\
(5.56)\end{array}$ \\
\hline$(X-\bar{X})$ & & & $\begin{array}{c}0.05 \\
(0.10)\end{array}$ & $\begin{array}{c}0.07 \\
(0.11)\end{array}$ \\
\hline other $^{*}(X-\bar{X})$ & & & $\begin{array}{c}0.11 \\
(0.10)\end{array}$ & $\begin{array}{c}0.10 \\
(0.10)\end{array}$ \\
\hline $\operatorname{tradeoff}{ }^{*}(X-\bar{X})$ & & & $\begin{array}{c}1.17^{* * *} \\
(0.27)\end{array}$ & $\begin{array}{l}1.14^{* * *} \\
(0.27)\end{array}$ \\
\hline other*tradeoff* $^{*}(X-\bar{X})$ & & & $\begin{array}{c}-1.77^{* * *} \\
(0.45)\end{array}$ & $\begin{array}{c}-1.73^{* * *} \\
(0.44)\end{array}$ \\
\hline Constant & $\begin{array}{c}51.08^{* * *} \\
(0.80)\end{array}$ & $\begin{array}{c}51.79^{* * *} \\
(0.96)\end{array}$ & $\begin{array}{c}51.08^{* * *} \\
(0.80)\end{array}$ & $\begin{array}{c}51.82^{* * *} \\
(0.96)\end{array}$ \\
\hline Observations & 2408 & 2408 & 2408 & 2408 \\
\hline Subjects & 86 & 86 & 86 & 86 \\
\hline
\end{tabular}

${ }^{*} p<0.10,{ }^{* *} p<0.05,{ }^{* * *} p<0.01$. Standard errors are clustered at the individual level and shown in parentheses. The dependent variables are lottery valuations $Y_{l}$ - i.e., in the charity-study: self-dollar valuations of self lotteries $\left(Y^{s}\left(P^{s}\right)\right)$ or charity lotteries $\left(Y^{s}\left(P^{c}\right)\right)$, and charity-dollar valuations of self lotteries $\left(Y^{c}\left(P^{s}\right)\right)$ or charity lotteries $\left(Y^{c}\left(P^{c}\right)\right)$; and in the partner-study: self-dollar valuations of self lotteries $\left(Y^{s}\left(P^{s}\right)\right)$ or partner lotteries $\left(Y^{s}\left(P^{p}\right)\right)$, and partner-dollar valuations of self lotteries $\left(Y^{p}\left(P^{s}\right)\right)$ or partner lotteries $\left(Y^{p}\left(P^{p}\right)\right)$. Valuations in self-dollars are scaled as percentages of $\$ 10$, and valuations in charity-dollars or partner-dollars are scaled as percentages of $\$ \mathrm{X}$. The results are from regressions of Equation 2 modified to include the shown interactions and modified such that charity is replaced by other (an indicator for charity or partner). $(X-\bar{X})$ is a participant's $\mathrm{X}$ minus the average $\mathrm{X}$. partner-study is an indicator for the partner study. For observations involving multiple switch points, the first switch point is assumed. Participants with censored $\mathrm{X}$ values or $\mathrm{X}$ values that resulted from decisions with multiple switch points are excluded. 


\section{Conclusion}

In examining how individuals respond to risk in charitable giving decisions, this study documents a novel pattern of behavior. When participants cannot use risk as an excuse not to give, in the no self-charity tradeoff context, they respond very similarly to risk in self lotteries and charity lotteries. However, when participants may use risk as an excuse not to give, in the self-charity tradeoff context, they act more averse to charity risk and less averse to self risk.

This excuse-driven interpretation is bolstered by documenting an individual level of consistency in excuse-driven behavior. Participants' extent of excuse-driven risk preferences is strongly correlated with their level of selfishness, and engagement in excuse-driven behavior in a moral wiggle room task, as developed in Dana et al. (2007). In an additional study, excuse-driven risk preferences are similarly strong when participants decide between payoffs for themselves and payoffs for another study participant.

As the observed excuse-driven risk preferences yield violations of transitivity ${ }^{29}$, these results may be most easily rationalized with a menu-dependent model that allows for different responses to risk depending on whether or not the environment permits excuses. ${ }^{30}$ Another possibility may involve fleshing out models where individuals infer their type based off of their own past behavior, but their inference about their prosocial tendencies is less informative in the presence of risk. ${ }^{31}$

Other fruitful avenues for future work may involve testing related policy implications. The evidence for excuse-driven types of individuals, in particular, indicates that charities may be able to exploit the heterogeneity in the types of potential donors when determining how to target fundraising requests. Potential implications for nonprofit organizations may also relate to other avenues for excuse-driven behavior in charitable giving; for instance, Exley (2015) demonstrates how individuals may use lower charity performance metrics as excuses not to give.

\footnotetext{
${ }^{29}$ For instance, $72 \%$ of participants have lower self-dollar valuations of charity lotteries, $Y^{s}\left(0.95^{c}\right)$, than comparable self-dollar valuations of self lotteries $Y^{s}\left(0.95^{s}\right)$, which implies $0.95^{c} \prec 0.95^{s}$. By contrast, $63 \%$ of participants do not have lower charity-dollar valuations of charity lotteries $Y^{c}\left(P^{c}\right)$ than comparable charity-dollar valuations of self lotteries $Y^{c}\left(0.95^{s}\right)$, which implies $0.95^{c} \succeq 0.95^{s}$. Assuming transitivity yields this particular preference reversal for $42 \%$ of the participants. A similarly high level of preference reversals exist for lottery valuations that exhibit the largest amount of excuse-driven risk preferences.

${ }^{30}$ One possibility may involve temptation models, such as Gul and Pesendorfer (2001), if "not giving" is classified as a tempting good. Interestingly though, previous literature, such as Andreoni et al. (2011), also discusses how "giving" may be considered a tempting good.

${ }^{31}$ That is, if individuals update both on their prosocial and risk preferences, then the strength of either signal may be reduced, such as when individuals may update on both their greedy and prosocial preferences in Bénabou and Tirole (2006).
} 


\section{References}

Andersson, Ola, Håkan J Holm, Jean-Robert Tyran, and Erik Wengström. 2013. "Risking other people's money: Experimental evidence on bonus schemes, competition, and altruism." IFN Working Paper.

Andersson, Ola, Håkan J Holm, Jean-Robert Tyran, and Erik Wengström. 2014. "Deciding for others reduces loss aversion." Management Science.

Andreoni, James. 1989. "Giving with Impure Altruism: Applications to Charity and Ricardian Equivalence." The Journal of Political Economy, 1447-1458.

Andreoni, James. 1990. "Impure Altruism and Donations to Public Goods: A Theory of Warm-Glow Giving." The Economic Journal, 100(401): 464-477.

Andreoni, James. 2006. "Chapter 18 Philanthropy." In Applications. Vol. 2 of Handbook on the Economics of Giving, Reciprocity and Altruism, , ed. Serge-Christophe Kolm and Jean Mercier Ythier, 1201 - 1269. Elsevier.

Andreoni, James, and B. Douglas Bernheim. 2009. "Social Image and the 50-50 Norm: A Theoretical and Experimental Analysis of Audience Effects." Econometrica, 77(5): 1607-1636.

Andreoni, James, and Charles Sprenger. 2011. "Uncertainty Equivalents: Testing the Limits of the Independence Axiom." NBER Working Paper No. 17342.

Andreoni, James, and Justin M. Rao. 2011. "The power of asking: How communication affects selfishness, empathy, and altruism." Journal of Public Economics, 95: 513-520.

Andreoni, James, and Ragan Petrie. 2004. "Public goods experiments without confidentiality: a glimpse into fund-raising." Journal of Public Economics, 88: 1605-1623.

Andreoni, James, Justin M. Rao, and Hannah Trachtman. 2011. "Avoiding the ask: A field experiment on altruism, empathy, and charitable giving." NBER Working Paper No. 17648.

Ariely, Dan, Anat Bracha, and Stephan Meier. 2009. "Doing Good or Doing Well? Image Motivation and Monetary Incentives in Behaving Prosocially." American Economic Review, 99(1): 544-555.

Azrielli, Yaron, Christopher P. Chambers, and Paul J. Healey. 2014. "Incentives in Experiments: A Theoretical Analysis." Working Paper.

Bartling, Björn, and Urs Fischbacher. 2012. "Shifting the Blame: On Delegation and Responsibility." Review of Economic Studies, 79(1): 67-87. 
Bartling, Björn, Florian Engl, and Roberto A. Weber. 2014. "Does willful ignorance deflect punishment? - An experimental study." European Economic Review, 70(0): 512 - 524 .

Batista, Catia, Dan Silverman, and Dean Yang. 2015. "Directed Giving: Evidence from an Inter-Household Transfer Experiment." Journal of Economic Behavior \& Organization.

Bénabou, Roland, and Jean Tirole. 2006. "Incentives and Prosocial Behavior." American Economic Review, 96(5): 1652-1678.

Bernheim, B. Douglas, and Christine L. Exley. 2015. "Understanding Conformity: An Experimental Investigation." Working Paper.

Bolton, Gary E., and Axel Ockenfels. 2010. "Betrayal aversion: Evidence from brazil, china, oman, switzerland, turkey, and the united states: Comment." American Economic Review, 628-633.

Brennan, Geoffrey, Luis G. González, Werner Güth, and M. Vittoria Levati. 2008. "Attitudes toward private and collective risk in individual and strategic choice situations." Journal of Economic Behavior \& Organization, 67(1): 253-262.

Broberg, Tomas, Tore Ellingsen, and Magnus Johannesson. 2007. "Is generosity involuntary?" Economics Letters, 94(1): 32-37.

Brock, J. Michelle, Andreas Lange, and Erkut Y. Ozbay. 2013. "Dictating the Risk: Experimental Evidence on Giving in Risky Environments." American Economic Review, 103(1): 415-437.

Brown, Alexander L., Jonathan Meer, and J. Forrest Williams. 2014. "Social Distance and Quality Ratings in Charity Choice." NBER Working Paper Series.

Carpenter, Jeffrey, and Caitlin Knowles Myers. 2010. "Why volunteer? Evidence on the role of altruism, image, and incentives." Journal of Public Economics, 94(11-12): 911 - 920.

Castillo, Marco, and David Eil. 2014. "Taring the Multiple Price List: Imperceptive Preferences and the Reversing of the Common Ratio Effect." Working Paper.

Castillo, Marco, Ragan Petrie, and Clarence Wardell. 2014. "Fundraising through online social networks: A field experiment on peer-to-peer solicitation." Journal of Public Economcis, 29-35.

Chakravarty, Sujoy, Glenn W. Harrison, Ernan E. Haruvy, and E. Elisabet Rutström. 2011. "Are you risk averse over other people's money?" Southern Economic Journal, 77(4): 901-913. 
Coffman, Lucas C. 2011. "Intermediation Reduces Punishment (and Reward)." American Economic Journal: Microeconomics, 3(4): 1-30.

Dana, Jason, Daylian M. Cain, and Robyn M. Dawes. 2006. "What you don't know won't hurt me: Costly (but quiet) exit in dictator games." Organizational Behavior and Human Decision Processes, 100: 193-201.

Dana, Jason, Roberto A. Weber, and Jason Xi Kuang. 2007. "Exploiting moral wiggle room: experiments demonstrating an illusory preference for fairness." Economic Theory, $33(67-80)$.

DellaVigna, Stefano, John List, and Ulrike Malmendier. 2012. "Testing for Altruism and Social Pressure in Charitable Giving." Quarterly Journal of Economics, 127(1): 1-56.

De Oliveira, Angela, Rachel T.A Croson, and Catherine Eckel. 2011. "The giving type: Identifying donors." Journal of Public Economics, 95(5): 428-435.

Engel, Christoph. 2011. "Dictator games: a meta study." Experimental Economics, 14(4): 583610.

Eriksen, Kristoffer, Ola Kvaløy, and Miguel Luzuriaga. 2014. "Risk-taking with Other People's Money." Working Paper.

Exley, Christine L. 2014. "Incentives for Prosocial Behavior: The Role of Reputations." Working Paper.

Exley, Christine L. 2015. "Using Charity Performance Metrics as an Excuse Not To Give." Working Paper.

Exley, Christine L., and Stephen J. Terry. 2015. "Wage Elasticities in Working and Volunteering: The Role of Reference Points in a Laboratory Study." Working Paper.

Falk, Armin, and Nora Szech. 2013. "Organizations, Diffused Pivotality and Immoral Outcomes." IZA Discussion Paper 7442.

Fong, Christina M., and Felix Oberholzer-Gee. 2011. "Truth in giving: Experimental evidence on the welfare effects of informed giving to the poor." Journal of Public Economics, 95: 436-444.

Gneezy, Uri, Elizabeth A. Keenan, and Ayelet Gneezy. 2014. "Avoiding overhead aversion in charity." Science, 346(6209): 632-635.

Grossman, Zachary. 2014. "Strategic ignorance and the robustness of social preferences." Management Science, 60(11): 2659-2665. 
Gul, Faruk, and Wolfgang Pesendorfer. 2001. "Temptation and Self-Control." Econometrica, 69(6): 1403-1435.

Güth, Werner M., Vittoria Levati, and Matteo Ploner. 2008. "On the social dimension of time and risk preferences: An experimental study." Economic Inquiry, 46(2): 261-272.

Haisley, Emily C., and Roberto A. Weber. 2010. "Self-serving interpretations of ambiguity in other-regarding behavior." Games and Economic Behavior, 68: 614-625.

Hamman, John R., George Loewenstein, and Roberto A. Weber. 2010. "Self-Interest through Delegation: An Additional Rationale for the Principal-Agent Relationship." American Economic Review, 100(4): 1826-1846.

Harbaugh, William T. 1998a. "The Prestige Motive for Making Charitable Transfers." The American Economic Review, 88(2): pp. 277-282.

Harbaugh, William T. 1998b. "What do donations buy?: A model of philanthropy based on prestige and warm glow." Journal of Public Economics, 67(2): 269 - 284.

Holt, Charles, and Susan Laury. 2002. "Risk Aversion and Incentive Effects." The American Economic Review, 92(5): 1644- 1655.

Iriberri, Nagore, and Pedro Rey-Biel. 2011. "The role of role uncertainty in modified dictator games." Experimental Economics, 14(2): 160-180.

Karlan, Dean, and Daniel H. Wood. 2014. "The effect of effectiveness: donor response to aid effectiveness in a direct mail fundraising experiment." NBER Working Paper Series, Working Paper $2004 \%$.

Konow, James. 2000. "Fair Shares: Accountability and Cognitive Dissonance in Allocation Decisions." The American Economic Review, 90(4): 1072-1092.

Krawczyk, Michal, and Fabrice Le Lec. 2010. "'Give me a chance!' An experiment in social decision under risk." Experimental Economics, 13(4): 500-511.

Lacetera, Nicola, and Mario Macis. 2010. "Social image concerns and prosocial behavior: Field evidence from a nonlinear incentive scheme." Journal of Economic Behavior and Organization, $76(2): 225-237$.

Landry, Craig, Andreas Lange, John A. List, Michael K. Price, and Nicholas G. Rupp. 2006. "Toward an understanding of the economics of charity: Evidence from a field experiment." The Quarterly Journal of Economics. 
Lazear, Edward P., Ulrike Malmendier, and Roberto A. Weber. 2012. "Sorting in experiments with application to social preferences." American Economic Journal: Applied Economics, 4(1): 136-163.

Linardi, Sera, and Margaret A. McConnell. 2011. "No excuses for good behavior: Volunteering and the social environment." Journal of Public Economics, 95: 445-454.

Li, Sherry Xin, Catherine Eckel, Philip J. Grossman, and Tara Larson Brown. 2013. "Who's in Charge? Donor Targeting Enhances Voluntary Giving to Government." Working paper.

Meer, Jonathan. 2014. "Effects of the price of charitable giving: Evidence from an online crowdfunding platform." Journal of Economic Behavior \& Organization, 103: 113-124.

Meier, Stephan, and Charles Sprenger. 2010. "Present-Biased Preferences and Credit Card Borrowing." American Economic Journal: Applied Economics, 2(1): 193-210.

Merritt, Anna C., Daniel A. Effron, and Benoît Monin. 2010. "Moral Self-Licensing: When Being Good Frees Us to Be Bad." Social and Personality Psychology Compass, 4(5): 344357.

Niehaus, Paul. 2014. "A Theory of Good Intentions." Working Paper.

Oberholzer-Gee, Felix, and Reiner Eichenberger. 2008. "Fairness in Extended Dictator Game Experiments." The B.E. Journal of Economic Analysis \& Policy, 8(1).

Prelec, Drazen. 1998. "The Probability Weighting Function.” Econometrica, 66(3): 497-527.

Small, Deborah A., and George Loewenstein. 2003. "Helping a Victim or Helping the Victim: Altruism and Identifiability." Journal of Risk and Uncertainty, 26(1): 5-16.

Tversky, Amos, and Daniel Kahneman. 1992. "Advances in Prospect Theory: Cumulative Representation of Uncertainty." Journal of Risk and Uncertainty, 5: 297-323.

van der Weele, Joël J., Julija Kulisa, Michael Kosfeld, and Guido Friebel. 2014. "Resisting Moral Wiggle Room: How Robust Is Reciprocal Behavior?" American Economic Journal: Microeconomics, 6(3): 256-264.

Vesterlund, Lise. 2006. "Why do people give?" In The Nonprofit Sector: A Research Handbook, 2nd Edition. , ed. Walter W. Powell and Richard Steinberg, 568-87. New Haven, CT:Yale University Press.

Yörük, Bariş K. 2013. "Charity Ratings." Working Paper. 


\section{A Instructions}

\section{A.1 Normalization Price List}

In this list:

- Option A will always be you receive $\$ 10$ dollars (and the ARC receives nothing).

- Option B will be the ARC receives some dollar amount (and you receive nothing). As you proceed down the rows of a list, the amount the ARC receives will increase from $\$ 0$ to $\$ 30$.

For each row, all you have to do is decide whether you prefer Option A or Option B. Indicate your preference by selecting the corresponding button. Most people begin by preferring Option A and then switch to Option $B$, so one way to complete this list is to determine the best row to switch from Option A to Option B.

Now, please make your decisions below.

\begin{tabular}{|c|c|}
\hline $\begin{array}{l}\text { Option A } \\
\text { you receive) }\end{array}$ & $\begin{array}{c}\text { Option B } \\
\text { (the ARC receives) }\end{array}$ \\
\hline You: $\$ 10$ & ARC: $\$ 0$ \\
\hline You: $\$ 10$ & ARC: $\$ 2$ \\
\hline You: $\$ 10$ & ARC: $\$ 4$ \\
\hline You: \$10 & ARC: $\$ 6$ \\
\hline You: $\$ 10$ & ARC: $\$ 8$ \\
\hline You: $\$ 10$ & ARC: $\$ 10$ \\
\hline You: $\$ 10$ & ARC: $\$ 12$ \\
\hline You: $\$ 10$ & ARC: $\$ 14$ \\
\hline You: $\$ 10$ & ARC: $\$ 16$ \\
\hline You: $\$ 10$ & ARC: $\$ 18$ \\
\hline You: $\$ 10$ & ARC: $\$ 20$ \\
\hline You: $\$ 10$ & ARC: $\$ 22$ \\
\hline You: \$10 & ARC: $\$ 24$ \\
\hline You: $\$ 10$ & ARC: $\$ 26$ \\
\hline You: \$10 & ARC: $\$ 28$ \\
\hline You: \$10 & ARC: $\$ 30$ \\
\hline
\end{tabular}




\section{A.2 Second Price List}

In this list:

- Option A will always be you receive $\$ 5$ dollars (and the ARC receives nothing).

- Option B will be the ARC receives some dollar amount (and you receive nothing). As you proceed down the rows of a list, the amount the ARC receives will increase from $\$ 0$ to $\$ 30$.

For each row, all you have to do is decide whether you prefer Option A or Option B. Indicate your preference by selecting the corresponding button. Most people begin by preferring Option A and then switch to Option B, so one way to complete this list is to determine the best row to switch from Option A to Option B.

Now, please make your decisions below.

\begin{tabular}{|c|c|}
\hline $\begin{array}{c}\text { Option A } \\
\text { (you receive) }\end{array}$ & $\begin{array}{c}\text { Option B } \\
\text { (the ARC receives) }\end{array}$ \\
\hline You: $\$ 5$ & ARC: $\$ 0$ \\
\hline You: $\$ 5$ & ARC: $\$ 2$ \\
\hline You: $\$ 5$ & ARC: $\$ 4$ \\
\hline You: $\$ 5$ & ARC: $\$ 6$ \\
\hline You: $\$ 5$ & ARC: $\$ 8$ \\
\hline You: $\$ 5$ & ARC: $\$ 10$ \\
\hline You: $\$ 5$ & ARC: $\$ 12$ \\
\hline You: $\$ 5$ & ARC: $\$ 14$ \\
\hline You: \$5 & ARC: $\$ 16$ \\
\hline You: $\$ 5$ & ARC: $\$ 18$ \\
\hline You: $\$ 5$ & ARC: $\$ 20$ \\
\hline You: $\$ 5$ & ARC: $\$ 22$ \\
\hline You: $\$ 5$ & ARC: $\$ 24$ \\
\hline You: $\$ 5$ & ARC: $\$ 26$ \\
\hline You: $\$ 5$ & ARC: $\$ 28$ \\
\hline You: $\$ 5$ & ARC: $\$ 30$ \\
\hline
\end{tabular}




\section{A.3 Valuation Price List: Example from Self Dollar Valuation of Self Lottery, $Y^{s}\left(P^{s}\right)$, Block}

In this list: - Option A will always be you receive $\$ 10$ dollars with probability 95\%, and $\$ 0$ otherwise (and the ARC
receives nothing).

- Option B will be you receive some dollar amount (and the ARC receives nothing). As you proceed down the rows of a list, the amount you receive will increase from $\$ 0$ to $\$ 10$.

For each row, all you have to do is decide whether you prefer Option A or Option B. Indicate your preference by selecting the corresponding button. Most people begin by preferring Option A and then switch to Option $B$, so one way to complete this list is to determine the best row to switch from Option A to Option B.

Now, please make your decisions below.

Option A

(you receive)

You: $\$ 10$ with probability $95 \%$, and $\$ 0$ otherwise

You: $\$ 10$ with probability $95 \%$, and $\$ 0$ otherwise

You: $\$ 10$ with probability $95 \%$, and $\$ 0$ otherwise

You: $\$ 10$ with probability $95 \%$, and $\$ 0$ otherwise

You: $\$ 10$ with probability $95 \%$, and $\$ 0$ otherwise

You: $\$ 10$ with probability $95 \%$, and $\$ 0$ otherwise

You: $\$ 10$ with probability $95 \%$, and $\$ 0$ otherwise

You: $\$ 10$ with probability $95 \%$, and $\$ 0$ otherwise

You: $\$ 10$ with probability $95 \%$, and $\$ 0$ otherwise

You: $\$ 10$ with probability $95 \%$, and $\$ 0$ otherwise

You: $\$ 10$ with probability $95 \%$, and $\$ 0$ otherwise

You: $\$ 10$ with probability $95 \%$, and $\$ 0$ otherwise

You: $\$ 10$ with probability $95 \%$, and $\$ 0$ otherwise

You: $\$ 10$ with probability $95 \%$, and $\$ 0$ otherwise

You: $\$ 10$ with probability $95 \%$, and $\$ 0$ otherwise

You: $\$ 10$ with probability $95 \%$, and $\$ 0$ otherwise

You: $\$ 10$ with probability $95 \%$, and $\$ 0$ otherwise

You: $\$ 10$ with probability $95 \%$, and $\$ 0$ otherwise

You: $\$ 10$ with probability $95 \%$, and $\$ 0$ otherwise

You: $\$ 10$ with probability $95 \%$, and $\$ 0$ otherwise

You: $\$ 10$ with probability $95 \%$, and $\$ 0$ otherwise

\section{Option B}

(you)

You: $\$ 0$

You: $\$ 0.50$

You: $\$ 1$

You: $\$ 1.50$

You: \$2

You: $\$ 2.50$

You: \$3

You: $\$ 3.50$

You: \$4

You: $\$ 4.50$

You: $\$ 5$

You: $\$ 5.50$

You: $\$ 6$

You: $\$ 6.50$

You: $\$ 7$

You: $\$ 7.50$

You: $\$ 8$

You: $\$ 8.50$

You: $\$ 9$

You: $\$ 9.50$

You: \$10 


\section{A.4 Valuation Price List: Example from Charity Dollar Valuation of Charity Lottery, $Y^{c}\left(P^{c}\right)$, Block}

In this list:

- Option A will always be the ARC receives $\$ 20$ dollars with probability $95 \%$, and $\$ 0$ otherwise (and you receive nothing).

- Option B will be the ARC receives some dollar amount (and you receive nothing). As you proceed down the rows of a list, the amount the ARC receives will increase from $\$ 0$ to $\$ 20$.

For each row, all you have to do is decide whether you prefer Option A or Option B. Indicate your preference by selecting the corresponding button. Most people begin by preferring Option A and then switch to Option $B$, so one way to complete this list is to determine the best row to switch from Option A to Option B.

Now, please make your decisions below.

Option A

(the ARC receives)

ARC: $\$ 20$ with probability $95 \%$, and $\$ 0$ otherwise

ARC: $\$ 20$ with probability $95 \%$, and $\$ 0$ otherwise

ARC: $\$ 20$ with probability $95 \%$, and $\$ 0$ otherwise

ARC: $\$ 20$ with probability $95 \%$, and $\$ 0$ otherwise

ARC: $\$ 20$ with probability $95 \%$, and $\$ 0$ otherwise

ARC: $\$ 20$ with probability $95 \%$, and $\$ 0$ otherwise

ARC: $\$ 20$ with probability $95 \%$, and $\$ 0$ otherwise

ARC: $\$ 20$ with probability $95 \%$, and $\$ 0$ otherwise

ARC: $\$ 20$ with probability $95 \%$, and $\$ 0$ otherwise

ARC: $\$ 20$ with probability 95\%, and $\$ 0$ otherwise

ARC: $\$ 20$ with probability $95 \%$, and $\$ 0$ otherwise

ARC: $\$ 20$ with probability $95 \%$, and $\$ 0$ otherwise

ARC: $\$ 20$ with probability $95 \%$, and $\$ 0$ otherwise

ARC: $\$ 20$ with probability $95 \%$, and $\$ 0$ otherwise

ARC: $\$ 20$ with probability $95 \%$, and $\$ 0$ otherwise

ARC: $\$ 20$ with probability $95 \%$, and $\$ 0$ otherwise

ARC: $\$ 20$ with probability $95 \%$, and $\$ 0$ otherwise

ARC: $\$ 20$ with probability $95 \%$, and $\$ 0$ otherwise

ARC: $\$ 20$ with probability $95 \%$, and $\$ 0$ otherwise

ARC: $\$ 20$ with probability $95 \%$, and $\$ 0$ otherwise

ARC: $\$ 20$ with probability $95 \%$, and $\$ 0$ otherwise

\section{Option B}

(the ARC receives)

ARC: $\$ 0$

ARC: $\$ 1$

ARC: $\$ 2$

ARC: $\$ 3$

ARC: $\$ 4$

ARC: $\$ 5$

ARC: $\$ 6$

ARC: $\$ 7$

ARC: $\$ 8$

ARC: $\$ 9$

ARC: $\$ 10$

ARC: $\$ 11$

ARC: $\$ 12$

ARC: $\$ 13$

ARC: $\$ 14$

ARC: $\$ 15$

ARC: $\$ 16$

ARC: $\$ 17$

ARC: $\$ 18$

ARC: $\$ 19$

ARC: $\$ 20$ 


\title{
A.5 Valuation Price List: Example from Self Dollar Valuation of Charity Lottery, $Y^{s}\left(P^{c}\right)$, Block
}

In this list:

\begin{abstract}
- Option A will always be the ARC receives $\$ 20$ dollars with probability $95 \%$, and $\$ 0$ otherwise (and you receive nothing).
\end{abstract}

- Option B will be you receive some dollar amount (and the ARC receives nothing). As you proceed down the rows of a list, the amount you receive will increase from $\$ 0$ to $\$ 10$.

For each row, all you have to do is decide whether you prefer Option A or Option B. Indicate your preference by selecting the corresponding button. Most people begin by preferring Option $A$ and then switch to Option B, so one way to complete this list is to determine the best row to switch from Option A to Option B.

Now, please make your decisions below.
Option A (the ARC receives)
Option B (you)
- ARC: $\$ 20$ with probability 95\%, and \$0 otherwise
You: $\$ 0$
ARC: $\$ 20$ with probability $95 \%$, and $\$ 0$ otherwise
You: $\$ 0.50$
ARC: $\$ 20$ with probability $95 \%$, and $\$ 0$ otherwise
You: \$1
ARC: $\$ 20$ with probability $95 \%$, and $\$ 0$ otherwise
ARC: $\$ 20$ with probability $95 \%$, and $\$ 0$ otherwise
You: $\$ 1.50$
ARC: $\$ 20$ with probability $95 \%$, and $\$ 0$ otherwise
You: $\$ 2$
ARC: $\$ 20$ with probability $95 \%$, and $\$ 0$ otherwise
You: $\$ 2.50$
ARC: $\$ 20$ with probability $95 \%$, and $\$ 0$ otherwise
You: $\$ 3$
ARC: $\$ 20$ with probability $95 \%$, and $\$ 0$ otherwise
You: $\$ 3.50$
ARC: $\$ 20$ with probability $95 \%$, and $\$ 0$ otherwise
You: \$4
ARC: $\$ 20$ with probability $95 \%$, and $\$ 0$ otherwise
You: $\$ 4.50$
ARC: $\$ 20$ with probability $95 \%$, and $\$ 0$ otherwise
You: $\$ 5$
ARC: $\$ 20$ with probability $95 \%$, and $\$ 0$ otherwise
You: $\$ 5.50$
You: $\$ 6$
ARC: $\$ 20$ with probability $95 \%$, and $\$ 0$ otherwise
You: $\$ 6.50$
ARC: $\$ 20$ with probability $95 \%$, and $\$ 0$ otherwise
You: $\$ 7$
ARC: $\$ 20$ with probability $95 \%$, and $\$ 0$ otherwise
You: $\$ 7.50$
ARC: $\$ 20$ with probability $95 \%$, and $\$ 0$ otherwise
You: $\$ 7.50$
ARC: $\$ 20$ with probability $95 \%$, and $\$ 0$ otherwise
You: $\$ 8$
ARC: $\$ 20$ with probability $95 \%$, and $\$ 0$ otherwise
You: $\$ 8.50$
ARC: $\$ 20$ with probability $95 \%$, and $\$ 0$ otherwise
You: $\$ 9$
ARC: $\$ 20$ with probability $95 \%$, and $\$ 0$ otherwise
You: $\$ 9.50$
ARC: $\$ 20$ with probability $95 \%$, and $\$ 0$ otherwise
You: $\$ 10$ 


\section{A.6 Valuation Price List: Example from Charity Dollar Valuation of Self Lottery, $Y^{c}\left(P^{s}\right)$, Block}

In this list:

- Option A will always be you receive $\$ 10$ dollars with probability $95 \%$, and $\$ 0$ otherwise (and the ARC receives nothing).

- Option B will be the ARC receives some dollar amount (and you receive nothing). As you proceed down the rows of a list, the amount the ARC receives will increase from $\$ 0$ to $\$ 20$.

For each row, all you have to do is decide whether you prefer Option A or Option B. Indicate your preference by selecting the corresponding button. Most people begin by preferring Option A and then switch to Option $B$, so one way to complete this list is to determine the best row to switch from Option A to Option B.

\section{Now, please make your decisions below.}

Option A (you receives)

You: $\$ 10$ with probability $95 \%$, and $\$ 0$ otherwise

You: $\$ 10$ with probability 95\%, and $\$ 0$ otherwise

You: $\$ 10$ with probability $95 \%$, and $\$ 0$ otherwise

You: $\$ 10$ with probability $95 \%$, and $\$ 0$ otherwise

You: $\$ 10$ with probability $95 \%$, and $\$ 0$ otherwise

You: $\$ 10$ with probability $95 \%$, and $\$ 0$ otherwise

You: $\$ 10$ with probability $95 \%$, and $\$ 0$ otherwise

You: $\$ 10$ with probability $95 \%$, and $\$ 0$ otherwise

You: $\$ 10$ with probability $95 \%$, and $\$ 0$ otherwise

You: $\$ 10$ with probability $95 \%$, and $\$ 0$ otherwise

You: $\$ 10$ with probability $95 \%$, and $\$ 0$ otherwise

You: $\$ 10$ with probability $95 \%$, and $\$ 0$ otherwise

You: $\$ 10$ with probability $95 \%$, and $\$ 0$ otherwise

You: $\$ 10$ with probability $95 \%$, and $\$ 0$ otherwise

You: $\$ 10$ with probability $95 \%$, and $\$ 0$ otherwise

You: $\$ 10$ with probability $95 \%$, and $\$ 0$ otherwise

You: $\$ 10$ with probability $95 \%$, and $\$ 0$ otherwise

You: $\$ 10$ with probability $95 \%$, and $\$ 0$ otherwise

You: $\$ 10$ with probability $95 \%$, and $\$ 0$ otherwise

You: $\$ 10$ with probability 95\%, and $\$ 0$ otherwise

You: $\$ 10$ with probability $95 \%$, and $\$ 0$ otherwise
Option B

(the ARC receives)

ARC: $\$ 0$

ARC: $\$ 1$

ARC: $\$ 2$

ARC: $\$ 3$

ARC: $\$ 4$

ARC: $\$ 5$

ARC: $\$ 6$

ARC: $\$ 7$

ARC: $\$ 8$

ARC: $\$ 9$

ARC: $\$ 10$

ARC: $\$ 11$

ARC: $\$ 12$

ARC: $\$ 13$

ARC: \$14

ARC: $\$ 15$

ARC: $\$ 16$

ARC: $\$ 17$

ARC: $\$ 18$

ARC: $\$ 19$

ARC: $\$ 20$ 


\title{
B Additional Lottery Valuation Results
}

\author{
Figure B.1: Estimates from Cumulative Prospect Theory
}

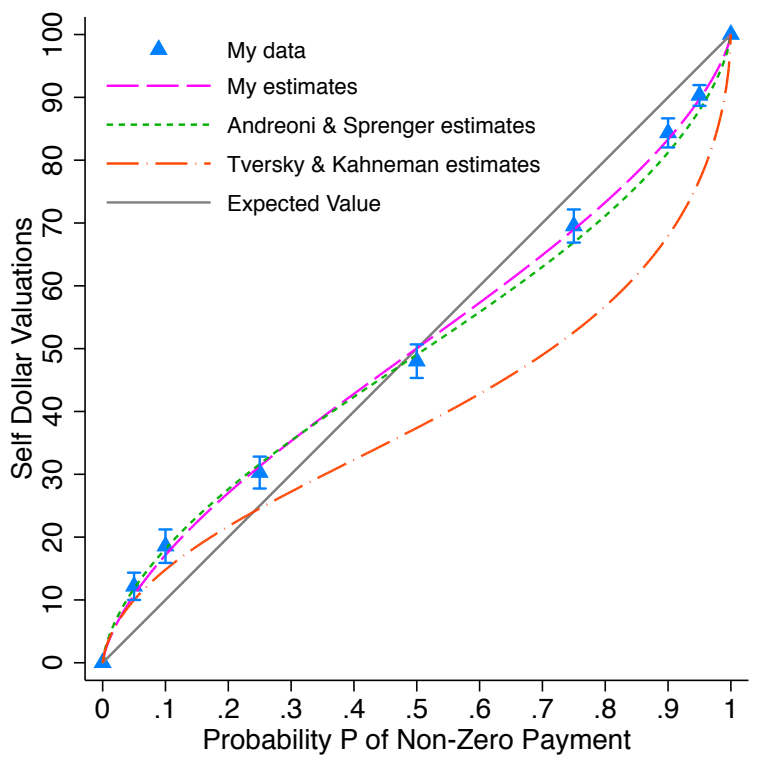

In following Tversky and Kahneman (1992), among many others, I assume a probability weighting function of $\pi(p)=p^{\gamma} /\left(\left(p^{\gamma}+(1-p)^{\gamma}\right)^{\frac{1}{\gamma}}\right)$ and a power bernoulli utility of $u(x)=x^{\alpha}$. Solving for the certainty equivalent or self-dollar valuation of the self lottery, $Y^{s}\left(P^{s}\right)$, as a function of $\mathrm{p}$ yields the following: $Y^{s}\left(P^{s}\right)=$ $\left[p^{\gamma} 10^{\alpha} /\left(\left(p^{\gamma}+(1-p)^{\gamma}\right)^{\frac{1}{\gamma}}\right)\right]^{\frac{1}{\alpha}}$. Estimating this equation via non-linear least squares with standard errors clustered at the individual level yields $\alpha=1.07(0.03)$ and $\gamma=0.77(0.02)$. These results include data for 99 participants (i.e., excludes the one participant whose $\mathrm{X}$ value resulted from decisions with multiple switch points). For the $1 \%$ of valuations involving multiple switch points, the first switch point is assumed. Andreoni \& Sprenger estimates are of the same equation given the $\alpha=1.07$ and $\gamma=0.73$ from Andreoni and Sprenger (2011). Tversky \& Kahnemann estimates are of the same equation given the $\alpha=0.88$ and $\gamma=0.61$ from Tversky and Kahneman (1992). 
Figure B.2: Decision Level Results

No Self-Charity Tradeoff

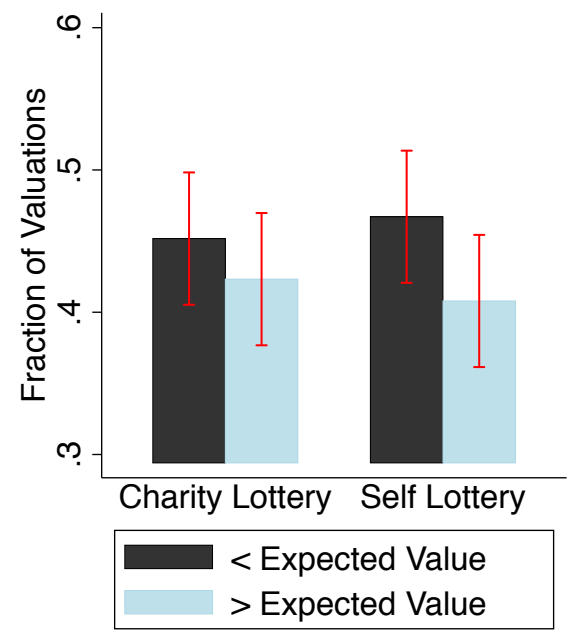

Self-Charity Tradeoff

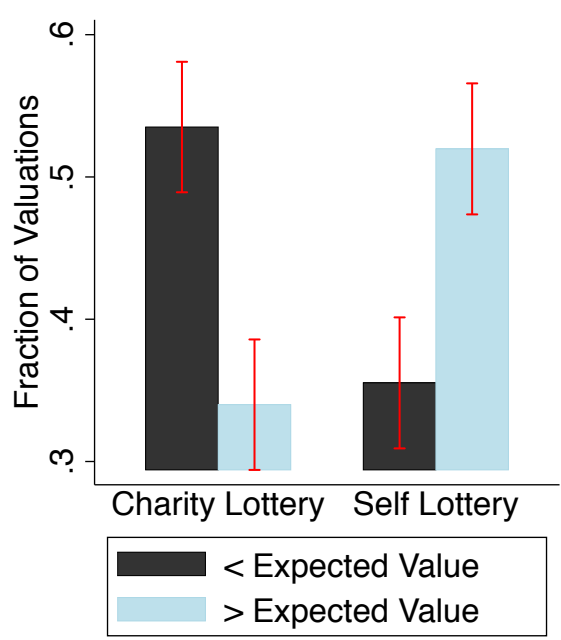

The error bars show the confidence interval for two standard errors. The calculations for the no self-charity tradeoff context result from the charity-dollar valuations of charity lotteries, $Y^{c}\left(P^{c}\right)$, and the self-dollar valuations of self lotteries, $Y^{s}\left(P^{s}\right)$. The calculations for the self-charity tradeoff context result from the self-dollar valuations of charity lotteries, $Y^{s}\left(P^{c}\right)$, and the charity-dollar valuations of self lotteries, $Y^{c}\left(P^{s}\right)$. Valuations in self-dollars are scaled as percentages of $\$ 10$, and valuations in charity-dollars are scaled as percentages of $\$ X_{i}$. The results include data for the 57 participants in my main subsample (i.e., excludes participants with $\mathrm{X}$ values that were censored or resulted from decisions with multiple switch points). For the $1 \%$ of valuations involving multiple switch points, the first switch point is assumed. 
Table B.1: Lottery Valuations in No Self-Charity Tradeoff Context

\begin{tabular}{|c|c|c|c|c|c|c|c|}
\hline \multirow{3}{*}{$\begin{array}{l}\text { Regression: } \\
\text { DV: }\end{array}$} & \multirow{2}{*}{\multicolumn{5}{|c|}{$\begin{array}{c}\text { Ordinary Least Squares } \\
\qquad Y_{l}\end{array}$}} & \multirow{3}{*}{$\begin{array}{c}\text { Interval } \\
Y_{l}^{\text {lower }} \\
Y_{l}^{\text {upper }} \\
6 \\
\end{array}$} & \multirow{3}{*}{$\begin{array}{c}\text { Tobit } \\
Y_{l} \\
7 \\
\end{array}$} \\
\hline & & & & & & & \\
\hline & 1 & 2 & 3 & 4 & 5 & & \\
\hline charity & $\begin{array}{c}0.06 \\
(0.82)\end{array}$ & $\begin{array}{c}0.06 \\
(0.82)\end{array}$ & $\begin{array}{c}0.24 \\
(0.87)\end{array}$ & $\begin{array}{l}-0.44 \\
(0.83)\end{array}$ & $\begin{array}{c}0.06 \\
(0.83)\end{array}$ & $\begin{array}{c}0.23 \\
(0.87)\end{array}$ & $\begin{array}{c}1.28 \\
(0.80)\end{array}$ \\
\hline$I(P=0.95)$ & & & & & $\begin{array}{c}79.17^{* * *} \\
(1.71)\end{array}$ & & \\
\hline$I(P=0.90)$ & & & & & $\begin{array}{c}74.04^{* * *} \\
(1.80)\end{array}$ & & \\
\hline$I(P=0.75)$ & & & & & $\begin{array}{c}60.33^{* * *} \\
(1.69)\end{array}$ & & \\
\hline$I(P=0.50)$ & & & & & $\begin{array}{c}38.46^{* * *} \\
(1.49)\end{array}$ & & \\
\hline$I(P=0.25)$ & & & & & $\begin{array}{c}18.64^{* * *} \\
(1.02)\end{array}$ & & \\
\hline$I(P=0.10)$ & & & & & $\begin{array}{c}6.14^{* * *} \\
(0.85)\end{array}$ & & \\
\hline Constant & $\begin{array}{c}51.79^{* * *} \\
(0.96)\end{array}$ & $\begin{array}{c}51.79^{* * *} \\
(0.41)\end{array}$ & $\begin{array}{c}51.88^{* * *} \\
(0.44)\end{array}$ & $\begin{array}{c}51.85^{* * *} \\
(0.41)\end{array}$ & $\begin{array}{c}12.25^{* * *} \\
(1.43)\end{array}$ & $\begin{array}{c}51.83^{* * *} \\
(0.97)\end{array}$ & $\begin{array}{c}50.50^{* * *} \\
(0.80)\end{array}$ \\
\hline Ind $\mathrm{FE}$ & no & yes & yes & yes & no & no & no \\
\hline Obs with MSP & yes & yes & no & no & yes & yes & yes \\
\hline Ind with MSP & yes & yes & yes & no & yes & yes & yes \\
\hline Censored X & no & no & no & no & no & no & yes \\
\hline Observations & 798 & 798 & 792 & 700 & 798 & 798 & 1386 \\
\hline Subjects & 57 & 57 & 57 & 50 & 57 & 57 & 99 \\
\hline
\end{tabular}

${ }^{*} p<0.10,{ }^{* *} p<0.05,{ }^{* * *} p<0.01$. Standard errors are clustered at the individual level and shown in parentheses. The dependent variables are lottery valuations $Y_{l}$ in the no self-charity tradeoff context - i.e., self-dollar valuations of self lotteries $\left(Y^{s}\left(P^{s}\right)\right)$, and charity-dollar valuations of charity lotteries $\left(Y^{c}\left(P^{c}\right)\right)$. Valuations in self-dollars are scaled as percentages of $\$ 10$, and valuations in charity-dollars are scaled as percentages of $\$ X_{i}$. The results are from regressions of $Y_{l i}=$ $\beta_{0}+\beta_{1}$ charity $_{l i}+\left(\sum_{P} \lambda_{P}+\sum_{i} \mu_{i}\right)+\epsilon_{l i}$, where $Y_{l i}$ is the valuation of a lottery $l$ by individual $i$ (in the case of the Tobit regression, this involves the upper and lower bounds of $Y_{l i}$ ); charity $_{l i}$ is an indicator for charity lotteries; $\lambda_{P}$ are fixed effects for lotteries with probability $P \in\{0.95$, $0.9,0.75,0.5,0.25,0.1\}\left(\mathrm{P}=0.05\right.$ excluded); $\mu_{i}$ are fixed effects for individual $i$ (individual $i=1$ excluded). Probability fixed effects are shown when included, and "Ind FE" indicates whether or not individual fixed effects are included. "Obs with MSP" and "Ind with MSP" indicate whether or not observations with, or individuals that have observations with multiple switch points, respectively, are included. When observations involving multiple switch points are included, the first switch point is assumed. "Censored X" indicates whether or not participants with censored X values are included. Note that 1 participant is always excluded because their $\mathrm{X}$ value resulted from decisions with multiple switch points. 
Table B.2: (Self - Charity) Lottery Valuations in No Self-Charity Tradeoff Context

\begin{tabular}{|c|c|c|c|c|}
\hline $\begin{array}{l}\text { Regression: } \\
\text { DV: }\end{array}$ & 1 & $\begin{array}{c}\text { ry Least } \\
D_{l} \\
2\end{array}$ & 3 & $\begin{array}{c}\text { Tobit } \\
D_{l} \\
4\end{array}$ \\
\hline$I(P=0.95)$ & $\begin{array}{l}-1.84^{*} \\
(0.95)\end{array}$ & $\begin{array}{l}-1.84^{*} \\
(0.95)\end{array}$ & $\begin{array}{c}-1.65^{*} \\
(0.97)\end{array}$ & $\begin{array}{c}-2.58^{* * *} \\
(0.86)\end{array}$ \\
\hline$I(P=0.90)$ & $\begin{array}{c}-3.60^{* * *} \\
(1.26)\end{array}$ & $\begin{array}{c}-3.60^{* * *} \\
(1.26)\end{array}$ & $\begin{array}{c}-3.25^{* *} \\
(1.33)\end{array}$ & $\begin{array}{c}-3.21^{* * *} \\
(1.02)\end{array}$ \\
\hline$I(P=0.75)$ & $\begin{array}{c}-3.03^{* *} \\
(1.32)\end{array}$ & $\begin{array}{c}-3.03^{* *} \\
(1.32)\end{array}$ & $\begin{array}{l}-2.40^{*} \\
(1.38)\end{array}$ & $\begin{array}{c}-4.75^{* * *} \\
(1.23)\end{array}$ \\
\hline$I(P=0.50)$ & $\begin{array}{c}0.70 \\
(1.73)\end{array}$ & $\begin{array}{c}0.82 \\
(1.69)\end{array}$ & $\begin{array}{c}1.90 \\
(1.57)\end{array}$ & $\begin{array}{l}-0.61 \\
(1.53)\end{array}$ \\
\hline$I(P=0.25)$ & $\begin{array}{l}2.11^{*} \\
(1.18)\end{array}$ & $\begin{array}{l}2.23^{*} \\
(1.20)\end{array}$ & $\begin{array}{l}2.50^{*} \\
(1.30)\end{array}$ & $\begin{array}{c}0.35 \\
(1.22)\end{array}$ \\
\hline$I(P=0.10)$ & $\begin{array}{c}2.72 \\
(1.86)\end{array}$ & $\begin{array}{c}2.00 \\
(1.71)\end{array}$ & $\begin{array}{l}3.50^{* *} \\
(1.57)\end{array}$ & $\begin{array}{c}1.97 \\
(1.29)\end{array}$ \\
\hline$I(P=0.05)$ & $\begin{array}{l}2.54^{* *} \\
(1.12) \\
\end{array}$ & $\begin{array}{l}2.23^{* *} \\
(1.10)\end{array}$ & $\begin{array}{l}2.50^{* *} \\
(1.19) \\
\end{array}$ & $\begin{array}{l}2.05^{* *} \\
(0.93) \\
\end{array}$ \\
\hline Ind FE & no & no & no & no \\
\hline Obs with MSP & yes & no & no & yes \\
\hline Ind with MSP & yes & yes & no & yes \\
\hline Censored X & no & no & no & yes \\
\hline Observations & 399 & 393 & 350 & 693 \\
\hline Subjects & 57 & 57 & 50 & 99 \\
\hline
\end{tabular}

${ }^{*} p<0.10,{ }^{* *} p<0.05,{ }^{* * *} p<0.01$. Standard errors are clustered at the individual level and shown in parentheses. The dependent variables are differences in lottery valuations $D_{P}$ in the no self-charity tradeoff context - i.e., self-dollar valuations of self lotteries minus charity-dollar valuations of charity lotteries $\left(Y^{s}\left(P^{s}\right)-Y^{c}\left(P^{c}\right)\right)$. Valuations in self-dollars are scaled as percentages of $\$ 10$, and valuations in charitydollars are scaled as percentages of $\$ X_{i}$. The results are from regressions of $D_{P i}=\sum_{P} \lambda_{P}+\epsilon_{i}$, where $D_{P i}$ is the difference in lottery valuations for probability $P$ by individual $i$; $\lambda_{P}$ are fixed effects for lotteries with probability $P \in\{0.95,0.9,0.75,0.5,0.25,0.1,0.05\}$. Probability fixed effects are shown, and "Ind FE" indicates whether or not individual fixed effects are included. "Obs with MSP" and "Ind with MSP" indicate whether or not observations with, or individuals that have observations with, multiple switch points are included. When observations involving multiple switch points are included, the first switch point is assumed. "Censored X" indicates whether or not participants with censored X values are included. Note that 1 participant is always excluded because their $\mathrm{X}$ value resulted from decisions with multiple switch points. 
Table B.3: Lottery Valuations in Self-Charity Tradeoff Context

\begin{tabular}{|c|c|c|c|c|c|c|c|}
\hline \multirow{3}{*}{$\begin{array}{l}\text { Regression: } \\
\text { DV: }\end{array}$} & \multicolumn{5}{|c|}{ Ordinary Least Squares } & \multirow{3}{*}{$\begin{array}{c}\text { Interval } \\
Y_{l}^{\text {lower }} \\
Y_{l}^{\text {upper }} \\
6\end{array}$} & \multirow{3}{*}{$\begin{array}{c}\text { Tobit } \\
Y_{l} \\
7\end{array}$} \\
\hline & & & $Y_{l}$ & & & & \\
\hline & 1 & 2 & 3 & 4 & 5 & & \\
\hline charity & $\begin{array}{c}-15.04^{* * *} \\
(3.22)\end{array}$ & $\begin{array}{c}-15.04^{* * *} \\
(3.22)\end{array}$ & $\begin{array}{c}-15.49^{* * *} \\
(3.31)\end{array}$ & $\begin{array}{c}-14.95^{\text {*** }} \\
(3.61)\end{array}$ & $\begin{array}{c}-15.04^{* * *} \\
(3.23)\end{array}$ & $\begin{array}{c}-16.28^{* * *} \\
(3.56)\end{array}$ & $\begin{array}{c}-46.64^{* * *} \\
(5.12)\end{array}$ \\
\hline$I(P=0.95)$ & & & & & $\begin{array}{c}61.60^{* * *} \\
(3.05)\end{array}$ & & \\
\hline$I(P=0.90)$ & & & & & $\begin{array}{c}58.60^{* * *} \\
(2.79)\end{array}$ & & \\
\hline$I(P=0.75)$ & & & & & $\begin{array}{c}49.01^{\text {*** }} \\
(2.29)\end{array}$ & & \\
\hline$I(P=0.50)$ & & & & & $\begin{array}{c}34.41^{* * *} \\
(2.04)\end{array}$ & & \\
\hline$I(P=0.25)$ & & & & & $\begin{array}{c}17.63^{* * *} \\
(1.86)\end{array}$ & & \\
\hline$I(P=0.10)$ & & & & & $\begin{array}{c}5.88^{* * *} \\
(1.25)\end{array}$ & & \\
\hline Constant & $\begin{array}{c}57.09^{* * *} \\
(2.01)\end{array}$ & $\begin{array}{c}57.09^{* * *} \\
(1.61)\end{array}$ & $\begin{array}{c}57.51^{* * *} \\
(1.65)\end{array}$ & $\begin{array}{c}56.79^{* * *} \\
(1.81) \\
\end{array}$ & $\begin{array}{c}24.65^{* * *} \\
(3.13)\end{array}$ & $\begin{array}{c}58.62^{* * *} \\
(2.32) \\
\end{array}$ & $\begin{array}{c}78.52^{* * *} \\
(3.46)\end{array}$ \\
\hline Ind $\mathrm{FE}$ & no & yes & yes & yes & no & no & no \\
\hline Obs with MSP & yes & yes & no & no & yes & yes & yes \\
\hline Ind with MSP & yes & yes & yes & no & yes & yes & yes \\
\hline Censored X & no & no & no & no & no & no & yes \\
\hline Observations & 798 & 798 & 784 & 700 & 798 & 798 & 1386 \\
\hline Subjects & 57 & 57 & 57 & 50 & 57 & 57 & 99 \\
\hline
\end{tabular}

${ }^{*} p<0.10,{ }^{* *} p<0.05,{ }^{* * *} p<0.01$. Standard errors are clustered at the individual level and shown in parentheses. The dependent variables are lottery valuations $Y_{l}$ in the self-charity tradeoff context - i.e., charity-dollar valuations of self lotteries $\left(Y^{c}\left(P^{s}\right)\right)$, and self-dollar valuations of charity lotteries $\left(Y^{s}\left(P^{c}\right)\right)$. Valuations in self-dollars are scaled as percentages of $\$ 10$, and valuations in charity-dollars are scaled as percentages of $\$ X_{i}$. The results are from regressions of $Y_{l i}=\beta_{0}+\beta_{1}$ charity $_{l i}+\left(\sum_{P} \lambda_{P}+\sum_{i} \mu_{i}\right)+\epsilon_{l i}$, where $Y_{l i}$ is the valuation of a lottery $l$ by individual $i$ (in the case of the Tobit regression, this involves the upper and lower bounds of $\left.Y_{l i}\right)$; charity $_{l i}$ is an indicator for charity lotteries; $\lambda_{P}$ are fixed effects for lotteries with probability $P \in\{0.95,0.9,0.75,0.5,0.25,0.1\}$ ( $\mathrm{P}=0.05$ excluded); $\mu_{i}$ are fixed effects for individual $i$ (individual $i=1$ excluded). Probability fixed effects are shown when included, and "Ind FE" indicates whether or not individual fixed effects are included. "Obs with MSP" and "Ind with MSP" indicate whether or not observations with, or individuals that have observations with, multiple switch points are included. When observations involving multiple switch points are included, the first switch point is assumed. "Censored X" indicates whether or not participants with censored X values are included. Note that 1 participant is always excluded because their $\mathrm{X}$ value resulted from decisions with multiple switch points. 
Table B.4: (Self - Charity) Lottery Valuations in Self-Charity Tradeoff Context

\begin{tabular}{|c|c|c|c|c|}
\hline $\begin{array}{l}\text { Regression: } \\
\text { DV: }\end{array}$ & 1 & $\begin{array}{c}\text { ry Least } \\
D_{l} \\
2\end{array}$ & 3 & $\begin{array}{c}\text { Tobit } \\
D_{l} \\
4\end{array}$ \\
\hline$I(P=0.95)$ & $\begin{array}{c}21.32^{* * *} \\
(4.01)\end{array}$ & $\begin{array}{c}20.97^{* * *} \\
(4.18)\end{array}$ & $\begin{array}{c}18.90^{* * *} \\
(4.31)\end{array}$ & $\begin{array}{c}43.71^{* * *} \\
(3.93)\end{array}$ \\
\hline$I(P=0.90)$ & $\begin{array}{c}21.27^{* * *} \\
(3.90)\end{array}$ & $\begin{array}{c}20.76^{* * *} \\
(3.94)\end{array}$ & $\begin{array}{c}19.35^{* * *} \\
(4.25)\end{array}$ & $\begin{array}{c}44.08^{* * *} \\
(3.90)\end{array}$ \\
\hline$I(P=0.75)$ & $\begin{array}{c}18.42^{* * *} \\
(3.97)\end{array}$ & $\begin{array}{c}18.75^{* * *} \\
(4.03)\end{array}$ & $\begin{array}{c}18.50^{* * * *} \\
(4.42)\end{array}$ & $\begin{array}{c}42.88^{* * *} \\
(4.01)\end{array}$ \\
\hline$I(P=0.50)$ & $\begin{array}{c}16.84^{* * *} \\
(3.77)\end{array}$ & $\begin{array}{c}17.27^{* * *} \\
(3.89)\end{array}$ & $\begin{array}{c}17.60^{* * * *} \\
(4.19)\end{array}$ & $\begin{array}{c}40.05^{* * *} \\
(4.14)\end{array}$ \\
\hline$I(P=0.25)$ & $\begin{array}{c}14.87^{* * *} \\
(3.99)\end{array}$ & $\begin{array}{c}15.50^{* * *} \\
(4.07)\end{array}$ & $\begin{array}{c}15.35^{* * *} \\
(4.42)\end{array}$ & $\begin{array}{c}38.18^{* * *} \\
(4.33)\end{array}$ \\
\hline$I(P=0.10)$ & $\begin{array}{c}9.25^{* * *} \\
(3.31)\end{array}$ & $\begin{array}{c}10.51^{* * *} \\
(3.41)\end{array}$ & $\begin{array}{c}9.50^{* * *} \\
(3.47)\end{array}$ & $\begin{array}{c}33.79^{* * *} \\
(4.33)\end{array}$ \\
\hline$I(P=0.05)$ & $\begin{array}{c}3.29 \\
(3.00) \\
\end{array}$ & $\begin{array}{c}3.44 \\
(3.05) \\
\end{array}$ & $\begin{array}{l}5.45^{*} \\
(3.19) \\
\end{array}$ & $\begin{array}{c}28.59^{* * *} \\
(4.34)\end{array}$ \\
\hline Ind FE & no & no & no & no \\
\hline Obs with MSP & yes & no & no & yes \\
\hline Ind with MSP & yes & yes & no & yes \\
\hline Censored X & no & no & no & yes \\
\hline Observations & 399 & 386 & 350 & 693 \\
\hline Subjects & 57 & 57 & 50 & 99 \\
\hline
\end{tabular}

${ }^{*} p<0.10,{ }^{* *} p<0.05,{ }^{* * *} p<0.01$. Standard errors are clustered at the individual level and shown in parentheses. The dependent variables are differences in lottery valuations $D_{p}$ in the self-charity tradeoff context - i.e., charity-dollar valuations of self lotteries minus self-dollar valuations of charity lotteries $\left(Y^{c}\left(P^{s}\right)-Y^{s}\left(P^{c}\right)\right)$. Valuations in self-dollars are scaled as percentages of $\$ 10$, and valuations in charitydollars are scaled as percentages of $\$ X_{i}$. The results are from regressions of $D_{P i}=\sum_{P} \lambda_{P}+\epsilon_{i}$, where $D_{P i}$ is the difference in lottery valuations for probability $P$ by individual $i ; \lambda_{P}$ are fixed effects for lotteries with probability $P \in\{0.95,0.9,0.75,0.5,0.25,0.1,0.05\}$. Probability fixed effects are shown, and "Ind FE" indicates whether or not individual fixed effects are included. "Obs with MSP" and "Ind with MSP" indicate whether or not observations with, or individuals that have observations with, multiple switch points are included. When observations involving multiple switch points are included, the first switch point is assumed. "Censored X" indicates whether or not participants with censored X values are included. Note that 1 participant is always excluded because their $\mathrm{X}$ value resulted from decisions with multiple switch points. 
Table B.5: Charity Lottery Valuations

\begin{tabular}{lccccccc}
\hline \hline Regression: & \multicolumn{5}{c}{ Ordinary Least Squares } & \multicolumn{3}{c}{ Interval } & Tobit \\
DV: & 1 & 2 & $Y_{l}$ & & & $Y_{l}^{\text {lower }}, Y_{l}^{\text {upper }}$ & $Y_{l}$ \\
& $-9.79^{* * *}$ & $-9.79^{* * *}$ & $-9.98^{* * *}$ & $-9.57^{* * *}$ & $-9.79^{* * *}$ & $-9.72^{* * *}$ & $-19.91^{* * *}$ \\
\hline tradeoff & $(1.89)$ & $(1.89)$ & $(1.94)$ & $(2.13)$ & $(1.90)$ & $(1.95)$ & $(2.00)$ \\
& & & & & $66.97^{* * *}$ & & \\
$I(P=0.95)$ & & & & & $(2.42)$ & & \\
& & & & & $63.36^{* * *}$ & & \\
$I(P=0.90)$ & & & & & $(2.19)$ & & \\
& & & & & $52.28^{* * *}$ & & \\
$I(P=0.75)$ & & & & & $(1.85)$ & & \\
& & & & & $33.51^{* * *}$ & & \\
$I(P=0.50)$ & & & & & $(1.41)$ & & \\
& & & & & $15.35^{* * *}$ & & \\
$I(P=0.25)$ & & & & & $(1.19)$ & & \\
& & & & & $4.47^{* * *}$ & & \\
$I(P=0.10)$ & & & & & $(0.67)$ & & \\
& & & & & & \\
Constant & $51.85^{* * *}$ & $51.85^{* * *}$ & $52.13^{* * *}$ & $51.41^{* * *}$ & $18.14^{* * *}$ & $52.05^{* * *}$ & $51.75^{* * *}$ \\
& $(0.83)$ & $(0.94)$ & $(0.96)$ & $(1.06)$ & $(1.66)$ & $(0.87)$ & $(0.80)$ \\
\hline Ind FE & no & yes & yes & yes & no & no & no \\
Obs with MSP & yes & yes & no & no & yes & yes & yes \\
Ind with MSP & yes & yes & yes & no & yes & yes & yes \\
Censored X & no & no & no & no & no & no & yes \\
Observations & 798 & 798 & 788 & 700 & 798 & 798 & 1386 \\
Subjects & 57 & 57 & 57 & 50 & 57 & 57 & 99 \\
\hline \hline
\end{tabular}

${ }^{*} p<0.10,{ }^{* *} p<0.05,{ }^{* * *} p<0.01$. Standard errors are clustered at the individual level and shown in parentheses. The dependent variables are charity lottery valuations $Y_{l}$ - i.e., charity-dollar valuations of charity lotteries $\left(Y^{c}\left(P^{c}\right)\right)$, and self-dollar valuations of charity lotteries $\left(Y^{s}\left(P^{c}\right)\right)$. Valuations in selfdollars are scaled as percentages of $\$ 10$, and valuations in charity-dollars are scaled as percentages of $\$ X_{i}$. The results are from regressions of $Y_{l i}=\beta_{0}+\beta_{1}$ tradeoff $_{l i}+\left(\sum_{P} \lambda_{P}+\sum_{i} \mu_{i}\right)+\epsilon_{l i}$, where $Y_{l i}$ is the valuation of a lottery $l$ by individual $i$ (in the case of the Tobit regression, this involves the upper and lower bounds of $\left.Y_{l i}\right)$; tradeoff $l i$ is an indicator for valuations occurring in the self-charity tradeoff context; $\lambda_{P}$ are fixed effects for lotteries with probability $P \in\{0.95,0.9,0.75,0.5,0.25,0.1\}$ ( $\mathrm{P}=0.05$ excluded); $\mu_{i}$ are fixed effects for individual $i$ (individual $i=1$ excluded). Probability fixed effects are shown, and "Ind FE" indicates whether or not individual fixed effects are included. "Obs with MSP" and "Ind with MSP" indicate whether or not observations with, or individuals that have observations with, multiple switch points are included. When observations involving multiple switch points are included, the first switch point is assumed. "Censored X" indicates whether or not participants with censored X values are included. Note that 1 participant is always excluded because their $\mathrm{X}$ value resulted from decisions with multiple switch points. 
Table B.6: Self Lottery Valuations

\begin{tabular}{|c|c|c|c|c|c|c|c|}
\hline \multirow{3}{*}{$\begin{array}{l}\text { Regression: } \\
\text { DV: }\end{array}$} & \multicolumn{5}{|c|}{ Ordinary Least Squares } & \multirow{3}{*}{$\begin{array}{c}\text { Interval } \\
Y_{l}^{\text {lower }}, Y_{l}^{\text {upper }} \\
6\end{array}$} & \multirow{3}{*}{$\begin{array}{c}\text { Tobit } \\
Y_{l} \\
7\end{array}$} \\
\hline & & & $Y_{l}$ & & & & \\
\hline & 1 & 2 & 3 & 4 & 5 & & \\
\hline tradeoff & $\begin{array}{l}5.30^{* *} \\
(2.02)\end{array}$ & $\begin{array}{l}5.30^{* *} \\
(2.02)\end{array}$ & $\begin{array}{c}5.56^{* * *} \\
(2.03)\end{array}$ & $\begin{array}{l}4.94^{* *} \\
(2.21)\end{array}$ & $\begin{array}{l}5.30^{* *} \\
(2.02)\end{array}$ & $\begin{array}{c}6.90^{* * *} \\
(2.34)\end{array}$ & $\begin{array}{c}28.68^{* * *} \\
(3.85)\end{array}$ \\
\hline$I(P=0.95)$ & & & & & $\begin{array}{c}73.79^{* * *} \\
(1.87)\end{array}$ & & \\
\hline$I(P=0.90)$ & & & & & $\begin{array}{c}69.28^{* * *} \\
(1.86)\end{array}$ & & \\
\hline$I(P=0.75)$ & & & & & $\begin{array}{c}57.06^{* * *} \\
(1.71)\end{array}$ & & \\
\hline$I(P=0.50)$ & & & & & $\begin{array}{c}39.36^{* * *} \\
(1.68)\end{array}$ & & \\
\hline$I(P=0.25)$ & & & & & $\begin{array}{c}20.92^{* * *} \\
(1.47)\end{array}$ & & \\
\hline$I(P=0.10)$ & & & & & $\begin{array}{c}7.54^{* * *} \\
(1.09)\end{array}$ & & \\
\hline Constant & $\begin{array}{c}51.79^{* * *} \\
(0.96)\end{array}$ & $\begin{array}{c}51.79^{* * *} \\
(1.01)\end{array}$ & $\begin{array}{c}51.84^{* * *} \\
(1.01)\end{array}$ & $\begin{array}{c}51.85^{* * *} \\
(1.11)\end{array}$ & $\begin{array}{c}13.51^{* * *} \\
(1.39)\end{array}$ & $\begin{array}{c}51.83^{* * *} \\
(0.97)\end{array}$ & $\begin{array}{c}50.51^{* * *} \\
(0.80)\end{array}$ \\
\hline $\begin{array}{l}\text { lnsigma } \\
\text { Constant }\end{array}$ & & & & & & $\begin{array}{c}3.50^{* * *} \\
(0.02)\end{array}$ & \\
\hline Ind $\mathrm{FE}$ & no & yes & yes & yes & no & no & no \\
\hline Obs with MSP & yes & yes & no & no & yes & yes & yes \\
\hline Ind with MSP & yes & yes & yes & no & yes & yes & yes \\
\hline Censored X & no & no & no & no & no & no & yes \\
\hline Observations & 798 & 798 & 788 & 700 & 798 & 798 & 1386 \\
\hline Subjects & 57 & 57 & 57 & 50 & 57 & 57 & 99 \\
\hline
\end{tabular}

${ }^{*} p<0.10,{ }^{* *} p<0.05,{ }^{* * *} p<0.01$. Standard errors are clustered at the individual level and shown in parentheses. The dependent variables are self lottery valuations $Y_{l}$ - i.e., self-dollar valuations of self lotteries $\left(Y^{s}\left(P^{s}\right)\right)$, and charity-dollar valuations of self lotteries $\left(Y^{c}\left(P^{s}\right)\right)$. Valuations in self-dollars are scaled as percentages of $\$ 10$, and valuations in charity-dollars are scaled as percentages of $\$ X_{i}$. The results are from regressions of $Y_{l i}=\beta_{0}+\beta_{1}$ tradeoff $_{l i}+\left(\sum_{P} \lambda_{P}+\sum_{i} \mu_{i}\right)+\epsilon_{l i}$, where $Y_{l i}$ is the valuation of a lottery $l$ by individual $i$ (in the case of the Tobit regression, this involves the upper and lower bounds of $\left.Y_{l i}\right)$; tradeoff $_{l i}$ is an indicator for valuations occurring in the self-charity tradeoff context; $\lambda_{P}$ are fixed effects for lotteries with probability $P \in\{0.95,0.9,0.75,0.5,0.25,0.1\}$ ( $\mathrm{P}=0.05$ excluded); $\mu_{i}$ are fixed effects for individual $i$ (individual $i=1$ excluded). Probability fixed effects are shown, and "Ind FE" indicates whether or not individual fixed effects are included. "Obs with MSP" and "Ind with MSP" indicate whether or not observations with, or individuals that have observations with, multiple switch points are included. When observations involving multiple switch points are included, the first switch point is assumed. "Censored X" indicates whether or not participants with censored X values are included. Note that 1 participant is always excluded because their $\mathrm{X}$ value resulted from decisions with multiple switch points. 
Table B.7: Lottery Valuations in Self Dollar Valuations

\begin{tabular}{|c|c|c|c|c|c|c|c|}
\hline \multirow{3}{*}{$\begin{array}{l}\text { Regression: } \\
\text { DV: }\end{array}$} & \multicolumn{5}{|c|}{ "Ordinary Least Squares } & \multirow{3}{*}{$\begin{array}{c}\text { Interval } \\
Y_{l}^{\text {lower }}, Y_{l}^{\text {upper }} \\
6\end{array}$} & \multirow{3}{*}{$\begin{array}{c}\text { Tobit } \\
Y_{l} \\
7\end{array}$} \\
\hline & & & $Y_{l}$ & & & & \\
\hline & 1 & 2 & 3 & 4 & 5 & & \\
\hline tradeoff & $\begin{array}{c}-9.74^{* * *} \\
(1.79)\end{array}$ & $\begin{array}{c}-9.74^{* * *} \\
(1.79)\end{array}$ & $\begin{array}{c}-9.90^{* * *} \\
(1.83)\end{array}$ & $\begin{array}{c}-10.01^{* * *} \\
(1.98)\end{array}$ & $\begin{array}{c}-9.74^{* * *} \\
(1.79)\end{array}$ & $\begin{array}{c}-9.51^{* * *} \\
(1.84)\end{array}$ & $\begin{array}{c}-18.67^{* * *} \\
(1.79)\end{array}$ \\
\hline$I(P=0.95)$ & & & & & $\begin{array}{c}64.78^{* * *} \\
(2.47)\end{array}$ & & \\
\hline$I(P=0.90)$ & & & & & $\begin{array}{c}60.29^{* * *} \\
(2.40)\end{array}$ & & \\
\hline$I(P=0.75)$ & & & & & $\begin{array}{c}49.50^{* * *} \\
(2.10)\end{array}$ & & \\
\hline$I(P=0.50)$ & & & & & $\begin{array}{c}32.59^{* * *} \\
(1.53)\end{array}$ & & \\
\hline$I(P=0.25)$ & & & & & $\begin{array}{c}15.13^{* * *} \\
(1.28)\end{array}$ & & \\
\hline$I(P=0.10)$ & & & & & $\begin{array}{c}4.56^{* * *} \\
(0.72)\end{array}$ & & \\
\hline Constant & $\begin{array}{c}51.79^{* * *} \\
(0.96)\end{array}$ & $\begin{array}{c}51.79^{* * *} \\
(0.89)\end{array}$ & $\begin{array}{c}51.97^{* * *} \\
(0.91)\end{array}$ & $\begin{array}{c}51.85^{* * *} \\
(0.99)\end{array}$ & $\begin{array}{c}19.39^{* * *} \\
(1.62)\end{array}$ & $\begin{array}{c}51.82^{* * *} \\
(0.97)\end{array}$ & $\begin{array}{c}50.49^{* * *} \\
(0.79)\end{array}$ \\
\hline Ind FE & no & yes & yes & yes & no & no & no \\
\hline Obs with MSP & yes & yes & no & no & yes & yes & yes \\
\hline Ind with MSP & yes & yes & yes & no & yes & yes & yes \\
\hline Censored X & no & no & no & no & no & no & yes \\
\hline Observations & 798 & 798 & 788 & 700 & 798 & 798 & 1386 \\
\hline Subjects & 57 & 57 & 57 & 50 & 57 & 57 & 99 \\
\hline
\end{tabular}

${ }^{*} p<0.10,{ }^{* *} p<0.05,{ }^{* * *} p<0.01$. Standard errors are clustered at the individual level and shown in parentheses. The dependent variables are lottery valuations elicited in self-dollar valuations $Y_{l}$ - i.e., self-dollar valuations of self lotteries $\left(Y^{s}\left(P^{s}\right)\right)$, and self-dollar valuations of charity lotteries $\left(Y^{s}\left(P^{c}\right)\right)$. Valuations in self-dollars are scaled as percentages of $\$ 10$. The results are from regressions of $Y_{l i}=\beta_{0}+$ $\beta_{1}$ charity $_{l i}+\left(\sum_{P} \lambda_{P}+\sum_{i} \mu_{i}\right)+\epsilon_{l i}$, where $Y_{l i}$ is the valuation of a lottery $l$ by individual $i$ (in the case of the Tobit regression, this involves the upper and lower bounds of $Y_{l i}$ ); tradeoff $l i$ is an indicator for valuations occurring in the self-charity tradeoff context; $\lambda_{P}$ are fixed effects for lotteries with probability $P$ $\in\{0.95,0.9,0.75,0.5,0.25,0.1\}$ ( $\mathrm{P}=0.05$ excluded); $\mu_{i}$ are fixed effects for individual $i$ (individual $i=1$ excluded). Probability fixed effects are shown, and "Ind FE" indicates whether or not individual fixed effects are included. "Obs with MSP" and "Ind with MSP" indicate whether or not observations with, or individuals that have observations with, multiple switch points are included. When observations involving multiple switch points are included, the first switch point is assumed. "Censored X" indicates whether or not participants with censored $\mathrm{X}$ values are included. Note that 1 participant is always excluded because their $\mathrm{X}$ value resulted from decisions with multiple switch points. 
Table B.8: Lottery Valuations in Charity Dollar Valuations

\begin{tabular}{|c|c|c|c|c|c|c|c|}
\hline \multirow{3}{*}{$\begin{array}{l}\text { Regression: } \\
\text { DV: }\end{array}$} & \multicolumn{5}{|c|}{ Ordinary Least Squares } & \multirow{3}{*}{$\begin{array}{c}\text { Interval } \\
Y_{l}^{\text {lower }}, Y_{l}^{\text {upper }} \\
6\end{array}$} & \multirow{3}{*}{$\begin{array}{c}\text { Tobit } \\
Y_{l} \\
7\end{array}$} \\
\hline & & & $Y_{l}$ & & & & \\
\hline & 1 & 2 & 3 & 4 & 5 & & \\
\hline tradeoff & $\begin{array}{l}5.24^{* *} \\
(1.97)\end{array}$ & $\begin{array}{l}5.24^{* *} \\
(1.97)\end{array}$ & $\begin{array}{c}5.41^{* * *} \\
(1.98)\end{array}$ & $\begin{array}{l}5.38^{* *} \\
(2.18)\end{array}$ & $\begin{array}{l}5.24^{* *} \\
(1.98)\end{array}$ & $\begin{array}{c}6.73^{* * *} \\
(2.28)\end{array}$ & $\begin{array}{c}27.77^{* * *} \\
(3.75)\end{array}$ \\
\hline$I(P=0.95)$ & & & & & $\begin{array}{c}75.99^{* * *} \\
(1.74)\end{array}$ & & \\
\hline$I(P=0.90)$ & & & & & $\begin{array}{c}72.35^{* * *} \\
(1.57)\end{array}$ & & \\
\hline$I(P=0.75)$ & & & & & $\begin{array}{c}59.85^{* * *} \\
(1.33)\end{array}$ & & \\
\hline$I(P=0.50)$ & & & & & $\begin{array}{c}40.29^{* * *} \\
(1.24)\end{array}$ & & \\
\hline$I(P=0.25)$ & & & & & $\begin{array}{c}21.14^{* * *} \\
(1.40)\end{array}$ & & \\
\hline$I(P=0.10)$ & & & & & $\begin{array}{c}7.46^{* * *} \\
(1.12)\end{array}$ & & \\
\hline Constant & $\begin{array}{c}51.85^{* * *} \\
(0.83)\end{array}$ & $\begin{array}{c}51.85^{* * *} \\
(0.99)\end{array}$ & $\begin{array}{c}52.04^{* * *} \\
(0.99)\end{array}$ & $\begin{array}{c}51.41^{* * *} \\
(1.09)\end{array}$ & $\begin{array}{c}12.27^{* * *} \\
(1.29)\end{array}$ & $\begin{array}{c}52.08^{* * *} \\
(0.88)\end{array}$ & $\begin{array}{c}51.89^{* * *} \\
(0.82)\end{array}$ \\
\hline Ind $\mathrm{FE}$ & no & yes & yes & yes & no & no & no \\
\hline Obs with MSP & yes & yes & no & no & yes & yes & yes \\
\hline Ind with MSP & yes & yes & yes & no & yes & yes & yes \\
\hline Censored X & no & no & no & no & no & no & yes \\
\hline Observations & 798 & 798 & 788 & 700 & 798 & 798 & 1386 \\
\hline Subjects & 57 & 57 & 57 & 50 & 57 & 57 & 99 \\
\hline
\end{tabular}

${ }^{*} p<0.10,{ }^{* *} p<0.05,{ }^{* * *} p<0.01$. Standard errors are clustered at the individual level and shown in parentheses. The dependent variables are lottery valuations elicited in charity-dollar valuations $Y_{l}$ i.e., charity-dollar valuations of charity lotteries $\left(Y^{c}\left(P^{c}\right)\right)$, and charity-dollar valuations of self lotteries $\left(Y^{c}\left(P^{s}\right)\right)$. Valuations in charity-dollars are scaled as percentages of $\$ X_{i}$. The results are from regressions of $Y_{l i}=\beta_{0}+\beta_{1}$ tradeoff $_{l i}+\left(\sum_{P} \lambda_{P}+\sum_{i} \mu_{i}\right)+\epsilon_{l i}$, where $Y_{l i}$ is the valuation of a lottery $l$ by individual $i$ (in the case of the Tobit regression, this involves the upper and lower bounds of $Y_{l i}$ ); tradeoff $l i$ is an indicator for valuations occurring in the self-charity tradeoff context; $\lambda_{P}$ are fixed effects for lotteries with probability $P \in\{0.95,0.9,0.75,0.5,0.25,0.1\}$ ( $\mathrm{P}=0.05$ excluded); $\mu_{i}$ are fixed effects for individual $i$ (individual $i=1$ excluded). Probability fixed effects are shown, and "Ind FE" indicates whether or not individual fixed effects are included. "Obs with MSP" and "Ind with MSP" indicate whether or not observations with, or individuals that have observations with, multiple switch points are included. When observations involving multiple switch points are included, the first switch point is assumed. "Censored $\mathrm{X}$ " indicates whether or not participants with censored X values are included. Note that 1 participant is always excluded because their $\mathrm{X}$ value resulted from decisions with multiple switch points. 
Table B.9: Examining Ordering Effects

\begin{tabular}{|c|c|c|c|c|}
\hline \multirow[t]{3}{*}{$\begin{array}{l}\text { Regression: } \\
\text { DV: }\end{array}$} & \multicolumn{4}{|c|}{$\begin{array}{c}\text { Ordinary Least Squares } \\
Y_{l}\end{array}$} \\
\hline & \multicolumn{2}{|c|}{$\begin{array}{l}\text { Charity Lotteries First Valued in } \\
\text { Self-Charity Tradeoff Context: }\end{array}$} & \multicolumn{2}{|c|}{$\begin{array}{l}\text { Self Lotteries First Valued in } \\
\text { Self-Charity Tradeoff Context }\end{array}$} \\
\hline & Yes & No & Yes & No \\
\hline charity & $\begin{array}{c}1.01 \\
(1.21)\end{array}$ & $\begin{array}{l}-1.25 \\
(1.00)\end{array}$ & $\begin{array}{l}-0.17 \\
(0.99)\end{array}$ & $\begin{array}{c}0.30 \\
(1.36)\end{array}$ \\
\hline tradeoff & $\begin{array}{l}5.38^{*} \\
(2.86)\end{array}$ & $\begin{array}{l}5.19^{*} \\
(2.81)\end{array}$ & $\begin{array}{c}4.61 \\
(3.16)\end{array}$ & $\begin{array}{l}6.07^{* *} \\
(2.48)\end{array}$ \\
\hline charity*tradeoff & $\begin{array}{c}-16.88^{* * *} \\
(4.53)\end{array}$ & $\begin{array}{c}-12.63^{* *} \\
(5.22)\end{array}$ & $\begin{array}{c}-14.43^{* *} \\
(5.44)\end{array}$ & $\begin{array}{c}-15.83^{* * *} \\
(4.00)\end{array}$ \\
\hline Constant & $\begin{array}{c}50.73^{* * *} \\
(0.97) \\
\end{array}$ & $\begin{array}{c}53.26^{* * * *} \\
(0.61) \\
\end{array}$ & $\begin{array}{c}51.80^{* * * *} \\
(0.90)\end{array}$ & $\begin{array}{c}51.79^{* * *} \\
(0.84) \\
\end{array}$ \\
\hline Ind FE & yes & yes & yes & yes \\
\hline Obs with MSP & yes & yes & yes & yes \\
\hline Ind with MSP & yes & yes & yes & yes \\
\hline Censored X & no & no & no & no \\
\hline Observations & 924 & 672 & 840 & 756 \\
\hline Subjects & 33 & 24 & 30 & 27 \\
\hline
\end{tabular}

${ }^{*} p<0.10,{ }^{* *} p<0.05,{ }^{* * *} p<0.01$. Standard errors are clustered at the individual level and shown in parentheses. The dependent variables are lottery valuations $Y_{l}$ - i.e., self-dollar valuations of self lotteries $\left(Y^{s}\left(P^{s}\right)\right)$, charity-dollar valuations of charity lotteries $\left(Y^{c}\left(P^{c}\right)\right)$, charity-dollar valuations of self lotteries $\left(Y^{c}\left(P^{s}\right)\right)$, and self-dollar valuations of charity lotteries $\left(Y^{s}\left(P^{c}\right)\right)$. Valuations in self-dollars are scaled as percentages of $\$ 10$, and valuations in charity-dollars are scaled as percentages of $\$ X_{i}$. The results are from regressions of Equation 2. "Ind FE" indicates whether or not individual fixed effects are included. "Obs with MSP" and "Ind with MSP" indicate whether or not observations with, or individuals that have observations with, multiple switch points are included. When observations involving multiple switch points are included, the first switch point is assumed. "Censored X" indicates whether or not participants with censored $\mathrm{X}$ values are included. Note that 1 participant is always excluded because their $\mathrm{X}$ value resulted from decisions with multiple switch points. 
Table B.10: Lottery Valuations in Partner Study

\begin{tabular}{|c|c|c|c|c|c|c|c|}
\hline \multirow{3}{*}{$\begin{array}{l}\text { Regression: } \\
\text { DV: }\end{array}$} & \multicolumn{5}{|c|}{ Ordinary Least Squares } & \multirow{3}{*}{$\begin{array}{c}\text { Interval } \\
Y_{l}^{\text {lower }}, Y_{l}^{\text {upper }} \\
6\end{array}$} & \multirow{3}{*}{$\begin{array}{c}\text { Tobit } \\
Y_{l} \\
7\end{array}$} \\
\hline & & & $Y_{l}$ & & & & \\
\hline & 1 & 2 & 3 & 4 & 5 & & \\
\hline charity & $\begin{array}{c}1.90 \\
(1.24)\end{array}$ & $\begin{array}{c}1.90 \\
(1.24)\end{array}$ & $\begin{array}{c}1.90 \\
(1.24)\end{array}$ & $\begin{array}{c}1.67 \\
(1.29)\end{array}$ & $\begin{array}{c}1.90 \\
(1.24)\end{array}$ & $\begin{array}{c}1.90 \\
(1.24)\end{array}$ & $\begin{array}{l}-0.02 \\
(1.53)\end{array}$ \\
\hline tradeoff & $\begin{array}{c}10.17^{* * *} \\
(3.41)\end{array}$ & $\begin{array}{c}10.17^{* * *} \\
(3.41)\end{array}$ & $\begin{array}{c}10.37^{* * *} \\
(3.39)\end{array}$ & $\begin{array}{c}11.59^{* * *} \\
(3.51)\end{array}$ & $\begin{array}{c}10.17^{* * *} \\
(3.42)\end{array}$ & $\begin{array}{c}12.07^{* * *} \\
(3.88)\end{array}$ & $\begin{array}{c}20.20^{* * *} \\
(3.99)\end{array}$ \\
\hline charity*tradeoff & $\begin{array}{c}-22.54^{* * *} \\
(5.25)\end{array}$ & $\begin{array}{c}-22.54^{* * *} \\
(5.25)\end{array}$ & $\begin{array}{c}-22.61^{* * *} \\
(5.28)\end{array}$ & $\begin{array}{c}-23.65^{* * *} \\
(5.57)\end{array}$ & $\begin{array}{c}-22.54^{* * *} \\
(5.27)\end{array}$ & $\begin{array}{c}-24.32^{* * *} \\
(5.72)\end{array}$ & $\begin{array}{c}-35.60^{* * *} \\
(5.40)\end{array}$ \\
\hline$I(P=0.95)$ & & & & & $\begin{array}{c}65.80^{* * *} \\
(2.25)\end{array}$ & & \\
\hline$I(P=0.90)$ & & & & & $\begin{array}{c}61.51^{* * *} \\
(2.29)\end{array}$ & & \\
\hline$I(P=0.75)$ & & & & & $\begin{array}{c}50.28^{* * *} \\
(2.16)\end{array}$ & & \\
\hline$I(P=0.50)$ & & & & & $\begin{array}{c}35.24^{* * *} \\
(1.59)\end{array}$ & & \\
\hline$I(P=0.25)$ & & & & & $\begin{array}{c}17.07^{* * *} \\
(1.20)\end{array}$ & & \\
\hline$I(P=0.10)$ & & & & & $\begin{array}{c}5.95^{* * *} \\
(0.65)\end{array}$ & & \\
\hline Constant & $\begin{array}{c}49.69^{* * *} \\
(1.42)\end{array}$ & $\begin{array}{c}49.69^{* * *} \\
(0.84)\end{array}$ & $\begin{array}{c}49.72^{* * *} \\
(0.83)\end{array}$ & $\begin{array}{c}50.17^{* * *} \\
(0.86)\end{array}$ & $\begin{array}{c}16.00^{* * *} \\
(1.79)\end{array}$ & $\begin{array}{c}49.69^{* * *} \\
(1.42)\end{array}$ & $\begin{array}{c}49.64^{* * *} \\
(1.10)\end{array}$ \\
\hline Ind FE & no & yes & yes & yes & no & no & no \\
\hline Obs with MSP & yes & yes & no & no & yes & yes & yes \\
\hline Ind with MSP & yes & yes & yes & no & yes & yes & yes \\
\hline Censored X & no & no & no & no & no & no & yes \\
\hline Observations & 812 & 812 & 810 & 756 & 812 & 812 & 1176 \\
\hline Subjects & 29 & 29 & 29 & 27 & 29 & 29 & 42 \\
\hline
\end{tabular}

${ }^{*} p<0.10,{ }^{* *} p<0.05,{ }^{* * *} p<0.01$. Standard errors are clustered at the individual level and shown in parentheses. The dependent variables are lottery valuations $Y_{l}$ - i.e., self-dollar valuations of self lotteries $\left(Y^{s}\left(P^{s}\right)\right.$ ), partnerdollar valuations of partner lotteries $\left(Y^{p}\left(P^{p}\right)\right)$, partner-dollar valuations of self lotteries $\left(Y^{p}\left(P^{s}\right)\right)$, and self-dollar valuations of partner lotteries $\left(Y^{s}\left(P^{p}\right)\right)$. Valuations in self-dollars are scaled as percentages of $\$ 10$, and valuations in charity-dollars are scaled as percentages of $\$ \mathrm{X}$. The results are from regressions of Equation 2 modified such that charity is replaced by partner. Probability fixed effects are shown when included, and "Ind FE" indicates whether or not individual fixed effects are included. "Obs with MSP" and "Ind with MSP" indicate whether or not observations with, or individuals that have observations with, multiple switch points are included. When observations involving multiple switch points are included, the first switch point is assumed. "Censored X" indicates whether or not participants with censored $\mathrm{X}$ values are included. Note that 2 participants are always excluded because their $\mathrm{X}$ values resulted from decisions with multiple switch points. 


\section{Additional Moral Wiggle Room Task Results}

Table C.1 shows the percentages of participants choosing A across the three questions. First, consider the cases where the state is always revealed - i.e., in the revealed-aligned-state question or revealed-unaligned-state question. When payoffs are aligned, $100 \%$ of participants choose the dominant option $A$, or their choices imply $A:(\$ 6, \$ 5) \succ B:(\$ 5, \$ 1)$. When payoffs are unaligned, only $44 \%$ choose the now selfish option $A$, or their choices imply $A:(\$ 6, \$ 1) \succ B:(\$ 5, \$ 5)$. This shows that most participants are willing to sacrifice some of their own payoffs in return for higher charity payoffs.

To begin considering if participants are more likely to choose the selfish option in the choice-toreveal question, let us first abstract away from whether or not participants reveal their state. ${ }^{32}$ For participants in the aligned state, their choices are nearly identical to their choices in the revealed-aligned-state question: $97.96 \%$ choose $A$. However, for participants in the unaligned state, their choices become substantially more selfish compared to their choices in the revealedunaligned-state question: $68.63 \%$ choose $A$. As shown in the third row of Table C.1, $68.63 \%$ of the participants choosing the selfish option is significantly larger than the $39.22 \%$ of the same participants who choose the selfish option in the revealed-unaligned-state question (a t-test rejects the equality of these percentages with $p<0.0001)$.

Table C.1: Percentage of Participants Choosing A According to Their State and Question Asked

\begin{tabular}{lcc}
\hline \hline & $\begin{array}{c}\text { Revealed-State } \\
\text { Questions }\end{array}$ & $\begin{array}{c}\text { Choice-to-Reveal } \\
\text { Question }\end{array}$ \\
\hline $\begin{array}{l}\text { For participants in: } \\
\text { Aligned State }\end{array}$ & $100.00 \%$ & $97.96 \%$ \\
$A:(\$ 6, \$ 5), B:(\$ 5, \$ 1)$ & $(\mathrm{n}=100)$ & $(\mathrm{n}=49)$ \\
Unaligned State & $44.00 \%$ & $68.63 \%$ \\
$A:(\$ 6, \$ 1), B:(\$ 5, \$ 5)$ & $(\mathrm{n}=100)$ & $(\mathrm{n}=51)$ \\
Unaligned State & $39.22 \%$ & $68.63 \%$ \\
$A:(\$ 6, \$ 1), B:(\$ 5, \$ 5)$ & $(\mathrm{n}=51)$ & $(\mathrm{n}=51)$ \\
\hline \hline
\end{tabular}

The bundle $(U, V)$ corresponds with the participant receiving $\$ \mathrm{U}$ and the charity receiving $\$ \mathrm{~V}$. n denotes the relevant sample size for each cell. In the third row, $*$ indicates that the sample is restricted to participants who had the aligned state payments of $A:(\$ 6, \$ 1)$ and $B:(\$ 5, \$ 5)$ in the choice-to-reveal question.

As shown in Table C.2, the increased selfish behavior in the choice-to-reveal question seems to result from participants avoiding information about whether or not their choice of $A$ is selfish.

\footnotetext{
${ }^{32}$ For participants who choose to reveal their state, the survey software, Qualtrics, randomly assigns them to one of the two states. For participants who do not choose to reveal their state, I replicate what Qualtrics would have done by randomly assigning them to one of the two states.
} 
For participants in the unaligned state, $54.90 \%$ choose to not reveal their state, and among these participants, $100 \%$ choose the selfish option $A$. Similarly, for participants in the aligned state, $55.10 \%$ chose not to reveal their state, and among these participants, $96.30 \%$ choose $A$. While choosing $A$ is not selfish in the aligned state, it provides the same evidence for excuse-driven behavior; from the perspective of the participants, they choose $A$ which maximizes their payoffs while avoiding information on whether or not $A$ also maximizes the charity's payoffs.

Table C.2: Percentage of Participants Choosing $A$ in Choice-to-Reveal Question

\begin{tabular}{lcc}
\hline \hline & \multicolumn{2}{c}{ Among participants who } \\
& Choose No Reveal & Choose Reveal \\
\hline Aligned State & $96.30 \%$ & $100.00 \%$ \\
$A:(\$ 6, \$ 5), B:(\$ 5, \$ 1)$ & $(\mathrm{n}=27)$ & $(\mathrm{n}=22)$ \\
Unaligned State & $100.00 \%$ & $30.43 \%$ \\
$A:(\$ 6, \$ 1), B:(\$ 5, \$ 5)$ & $(\mathrm{n}=28)$ & $(\mathrm{n}=23)$ \\
\hline \hline
\end{tabular}

The bundle $(U, V)$ corresponds with the participant receiving $\$ \mathrm{U}$ and the charity receiving $\$ \mathrm{~V}$. n denotes the relevant sample size for each cell. This data is only from the choice-to-reveal question, where participants could choose to reveal their state or choose not to reveal their state, before choosing $A$ or $B$. 